\title{
Influence of regeneration process parameters on geometry and defects of clearance surface of planer knives used in wood planing process
}

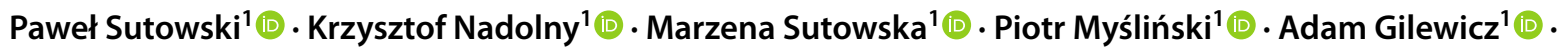 \\ Bogdan Warcholiński ${ }^{1}$ i]
}

Received: 31 August 2021 / Revised: 2 November 2021 / Accepted: 5 November 2021 / Published online: 13 January 2022

(c) The Author(s) 2022

\begin{abstract}
A properly implemented strategy regarding the planer knife regeneration process, may not only restore the original cutting ability of the tool, but even increase its operational quality, including its durability for industrial woodworking processes. This article presents experimental results and discussion in respect of sharpening planer knives with cubic boron nitride grinding wheels. Both the grinding conditions and machining surface quality were analyzed. Application of improper size or loads of abrasive grains may lead to the appearance of grinding burns on a machined surface, or result in a surface with cracks and grooves. The results of the measurements carried out indicate that surfaces with reduced values of roughness and waviness parameters can be obtained, even up to $22 \%$ (as in the case of the reduced peak height parameter, Spk) in relation to new knives, prepared at a factory. The value of $S t$ and $S d s$ parameters are almost the same as reference knife (deviation up to 3\%). Due to machining marks, the total waviness exceeds 33\%. Our research also shows that due to the technological quality of the knife surfaces, it is beneficial to use CBN grains with a low depth of cut ( $a_{\mathrm{e}}$ no more than $0.02 \mathrm{~mm}$ ), but a moderate or high feed rate (the best choice is about $470 \mathrm{~mm} / \mathrm{min}$ for $v_{\mathrm{ft}}$ ). Presented results constitute an important know-how for the grinding process with the use of grinders used by operators (like WEINIG Rondamat 980) during the sharpening of planer cutter heads in the wood industry.
\end{abstract}

Keywords Planer knives $\cdot$ Regeneration process $\cdot$ Grinding burns $\cdot$ Surface morphology quantification $\cdot$ Surface roughness

\begin{abstract}
Abbreviations
CBN Cubic boron nitride

HSS High-speed steel

$\alpha_{\mathrm{F}} \quad$ Contour rake angle, ${ }^{\circ}$
\end{abstract}

Krzysztof Nadolny

krzysztof.nadolny@tu.koszalin.pl

Paweł Sutowski

pawel.sutowski@tu.koszalin.pl

Marzena Sutowska

marzena.sutowska@tu.koszalin.pl

Piotr Myśliński

piotr.myslinski@tu.koszalin.pl

Adam Gilewicz

adam.gilewicz@tu.koszalin.pl

Bogdan Warcholiński

bogdan.warcholinski@tu.koszalin.pl

1 Faculty of Mechanical Engineering, Koszalin University of Technology, Racławicka 15-17, 75-620 Koszalin, Poland
$\beta_{\mathrm{F}} \quad$ Contour wedge angle, ${ }^{\circ}$

$\gamma_{\mathrm{F}} \quad$ Contour clearance angle, ${ }^{\circ}$

$\lambda_{\mathrm{c}} \quad$ Cutoff value (filter size), $\mathrm{mm}$

$a_{\mathrm{e}} \quad$ Depth of cut (aka: working engagement), mm

$G_{1} \quad$ Skewness of the distribution

$G_{2} \quad$ Kurtosis of distribution

$h_{\text {eq }} \quad$ Equivalent chip thickness, $\mu \mathrm{m}$

$n \quad$ Sample size,

$n_{\mathrm{s}} \quad$ Grinding wheel rotational speed, $\mathrm{rpm}$

$q \quad$ Grinding ratio of cutting speed to feed rate (aka: speed ratio)

$Q_{\mathrm{BL}} \quad$ Surface quality index,

$r w \quad$ Roughness to waviness relation ratio,

$R^{2}$ adj. Adjusted correlation coefficient

$\mathrm{Ra} \quad$ Arithmetic mean deviation of the roughness profile, $\mu \mathrm{m}$

$R k \quad$ Depth of the core roughness profile, $\mu \mathrm{m}$

$R t \quad$ Total height of the roughness profile, $\mu \mathrm{m}$

$R x \quad$ Max. depth of motifs, $\mu \mathrm{m}$

$R z \quad$ Maximum height of roughness profile, $\mu \mathrm{m}$ 


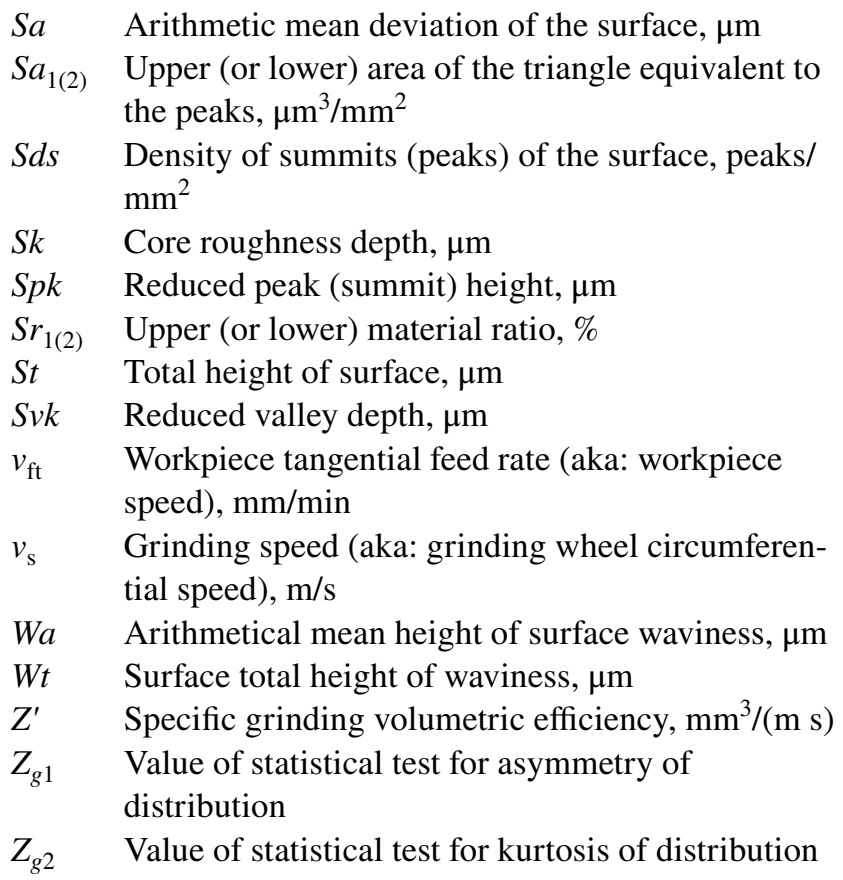

\section{Introduction}

The cutting ability of a machining tool and its life (related to the possibility of regeneration) are the key issues related to the economics of the material processing technology. Machining conditions that make intensive use of the tool's cutting capability are uneconomical because the costs of reconditioning (realized mainly in grinding operations) or replacing the tool with a new one are high. On the other hand, the use of low speeds and feed values, cause efficiency losses due to low production rate. A typical relationship between tool life to cutting speed can be written with Taylor's empirical equations, e.g. in basic or extended form [1]:

$v \cdot t^{n}=C$,

$t=\frac{C}{v^{1 / n} \cdot f^{1 / n_{1}} \cdot a_{e}^{1 / n_{2}}}$,

where $v$ is the cutting speed, $f$ is the feed rate, $a_{\mathrm{e}}$ is the depth of cut, $t$ is the tool life, and $n, n_{1}, n_{2}, C$ are constants.

The life expectancy of cutting tools is the subject of many scientific studies, which describe tool life criteria and indicate possibilities for monitoring the wear process or other forms of tool failure [2-7].

An investigation of the tool wear can be done on-line with the use of acoustic emission [7] or with other physical quantities observed during machining, for example: measure and evaluate force components or force to power ratio $[5,8,9]$.

A fundamental wear rate can be derived by considering abrasive or diffusion forms. Both are related to cutting parameters and cutting temperature, the effect of which is negative [1]. High-temperature problem and mechanical stability of a tool are the topic of research dedicated to finding new materials or modifying the mechanical properties of a tool by applying special protective coatings [10,11].

The research [10] shows the possibility to doubling the tool life if we use of multilayer thin anti-wear AlCrBN coating layer (with reference to unmodified tools). For industrial planer knives in pine wood planing process, the average value of the cutting edge radius is reduced about $18 \%$ with working twice as long under the same conditions.

Another solution that increases the efficiency of the cutting process and the tool life is to use appropriate cooling techniques like MQL (minimum quantity lubrication) or vortex cooling methods. The minimum quantity lubrication method covers the tool with a thin oil film, reducing friction, decrease of the cutting temperature and preventing wear [12, 13].

Clearly, any process or material improvements, or other efforts, can be beneficial. Thereby, this paper presents the results of a study focused on the process of sharpening planer knives, as a regeneration process, that allows the tool to be used repeatedly.

The wear process of machining tools can take on various forms. In the case of cutting or planing blades, we usually encounter their gradual blunting. Furthermore loss of cutting properties causes deterioration of the surface quality of the machined workpiece. In order for the process to proceed in accordance with the established quality standards, the tools must be replaced or their working surface regenerated.

Sharpening planer knives, which constitute a working element of the cutter head used in the longitudinal planing process of wood or wood-based materials, is an important preparatory stage of the machining process and allows companies to reduce the costs of technical production of products.

In most cases sharpening is carried out by the semi-automated or automated grinding machines, like Weinig Rondamat, and machining knife's clearance surface is running until the correct shape of the blade edge is restored. The end result of this process is subjectively evaluated by the grinder operator. The right results depend on his bias and experience. An important factor is also the selection of an appropriate assessment method, standards or procedures. The main goal is always to eliminate worn edge displacement and obtain a high degree of sharpness of the edge, assessed by the radius of the rounding of this edge.

This issue is the subject of numerous studies and scientific works. For example, the long-term use of planer knives leads to significant wear of the working edge, which can be described by cutting wear parameters, as worn edge displacement, nose width, rake face wear or the radius of the cutting edge $[10,14,15]$. Selected forms of wear, such as 
initial lapping, abrasive wear, cracking or chipping can be observed on the rake surface of the planer industrial planing knives with the use of microscopic observation and visual analysis. In some cases, wear in the form of cracks and material loss or abrasive wear may be so great that it requires an appropriate knife sharpening strategy [10, 15], especially in the case of $\mathrm{CrCN} / \mathrm{CrN}$ or AlCrN-coated planing blades. Those layers, formed by cathodic arc evaporation, have the critical force in the scratch test above $77 \mathrm{~N}$ and show HF1 class (according to Daimler-Benz test), which means they possess proper adhesion properties and are characterized by good wear resistance, as proved by an international team in $[16,17]$.

Multi-pass sharpening and joint quantitative and qualitative analysis of process may provide a partial solution to the problem of choosing the right abrasive tool and the method of machining blades. This issue is discussed in the works of Zhivko Gochev, Pavlin Vichev and Georgi Vukov, i.a. [18, 19]. Additionally, the process can be intensified to a capacity of more than $500 \mathrm{~mm}^{3} / \mathrm{min}$ using metal-coated synthetic diamond grains compared with phenol-formaldehyde-based organic bond grinding wheels. This is significant result due to the fact that the metal bond reduces the consumption of abrasive grains, while the machining process is carried out with less effective sharpening power consumption.

The experiments under different sharpening modes and abrasive wheels indicates the relationship between the effective power of direct and reverse motion and the rate of the cross-feed-it usually grows with an increase in cross feed value [19]. It can be found that the cutting ability decreases with an increase in cross-feed due to an increase in the repulsion forces between the grinding wheel and knife cutting edge.

To determine knife surface roughness and the maximum breakage deposits of the cutting edge, the measurements can be relatively easily carried out using optical and profilometry methods. Referring to the research results, the typical roughness of the ground surfaces is within the standard range of the Ra parameter $(0.2-0.8 \mu \mathrm{m})$, with a general tendency to increase with the rate of the cross-feed [20]. The statistical model of this correlation was presented in [21]. The size of the maximum breakage deposits of the cutting edge increases with increasing the cross-feed. The specific diamond consumption of a polycrystalline diamond grinding wheel, in relation to the mass of the take-down material, increases in a linear or exponential function of the crosswise feed. Sharpening with cooling helps to reduce the microindentations of the cutting edge [21].

The grinding wheel wear can be significant (7.5-10.5 g/ $\mathrm{mg}$ ) only in the case of grinding without cooling at a crossfeed value over $0.08 \mathrm{~mm} /$ double motion for a BM/A bond and over $0.15 \mathrm{~mm} /$ double motion for a B8/A bond with cooling. At the same time, these are the limits that the authors of the study established for the process to ensure proper machining results [20].

One of the most important conclusions of the work of Gochev et al. is the experimental proof that when sharpening flat knives made of type M2 HSS steel (P6M5), the operational productivity is increased by the use of CBN tools.

However, multi-criteria verification of the effect of grinding parameter conditions on the surface geometry of the planer tool is still lacking in known sources, or are difficult to compare and draw clear conclusions.

The research activities described in this article are part of a research project conducted in an effort to provide planer knives with greater efficiency than previously used in industrial practice. The main aim of the conducted research was to determine the geometric quality of knives designed for machining dry or wet soft wood (e.g. pine wood, Pinus sylvestris $\mathrm{L}$.) shaped in line with various processing parameters on an industrial grinding machine.

Thus, the paper is devoted to the study the possibility of obtaining knife surfaces with different textures. Knowledge concerning the influence of specific parameters of the grinding process on the result of the machining can be used in industry to increase the life of planer knives in the wood planing process. An additional but important feature of the presented results is the visualization of the difference between the microgeometry of knives sharpened in industrial conditions and new knives prepared by the manufacturer. An important aspect of the presented results is obtaining a surface after grinding with a quality index close to an sharp and unused knife.

\section{Materials and methods}

This study examined the influence of the grinding parameters on the morphology and texture of the clearance surface of industrial planer knife blades. Detailed analyses were carried out to determine how the surface microstructure of the knives changes with the use of different sizes of abrasive grain and various values of the specific volumetric efficiency of the grinding process.

For every set of testing parameters, microscopic observation with detailed visual analysis was carried out and selected texture parameters for roughness and waviness profiles were measured. The results were subjected to comparative analyses.

\subsection{Experimental details}

The grinding process of planer knives was conducted using a Rondamat 980 grinding machine manufactured by Michael Weinig AG (Tauberbischofsheim, Germany), as shown in Fig. 1. The Rondamat is a profile grinder designed for 
resharpening of straight planing knives in the cutterblock. It is also possible to sharpen and produce profile knives out of a raw blank according to a template. For the needs of the research project, this grinder was equipped with a grinding wheel spindle speed control system operating in the range of $1500-4600 \mathrm{rpm}$ with a $100 \mathrm{rpm}$ increment.

The other elements of the work station used to prepare the planer cutter head for grinding operations comprise the following: an OptiControl measuring and display system for optical control of the position and geometry of the knives mounted in the planer cutter head (Fig. 1b) and precision setting stand for the planer cutter heads (Fig. 1c). The working range of the OptiControl station $(158 \mathrm{~mm}$ in a radial direction and $325 \mathrm{~mm}$ in an axial direction) fully covered the requirements for the used planer cutter heads with a diameter and height of $160 \mathrm{~mm}$. The use of OptiControl and a precision setting stand for planer cutter heads allowed for precise placement of the set of knives in order that their cutting edges were at a distance of $(81.5 \pm 0.01) \mathrm{mm}$ from the axis of rotation of the cutter head (total diameter with knives: $163 \mathrm{~mm}$ ).

Bonded grinding wheels made by DIAMENTPOL S.J. (Katowice, Poland) were used in the grinding process, in the form of a grinding wheel with a metal body and a composite layer of cubic boron nitride (CBN) grains with a ceramic binder intended for wet grinding-WI13TM $125 \times 3 \times 4 \times 20$ B151 V240 M wet (Fig. 2). This is in accordance with tool manufacturers' recommendations for machining high-speed steels (HSS). SEM-based morphological analysis of the CBN grains is included in the paper [22]. The characteristics of the grinding wheels used were constant apart from the grain size (Table 1).

The research methodology included grinding planer knives in sets of 6 , embedded in GOLPOL GH-3.00

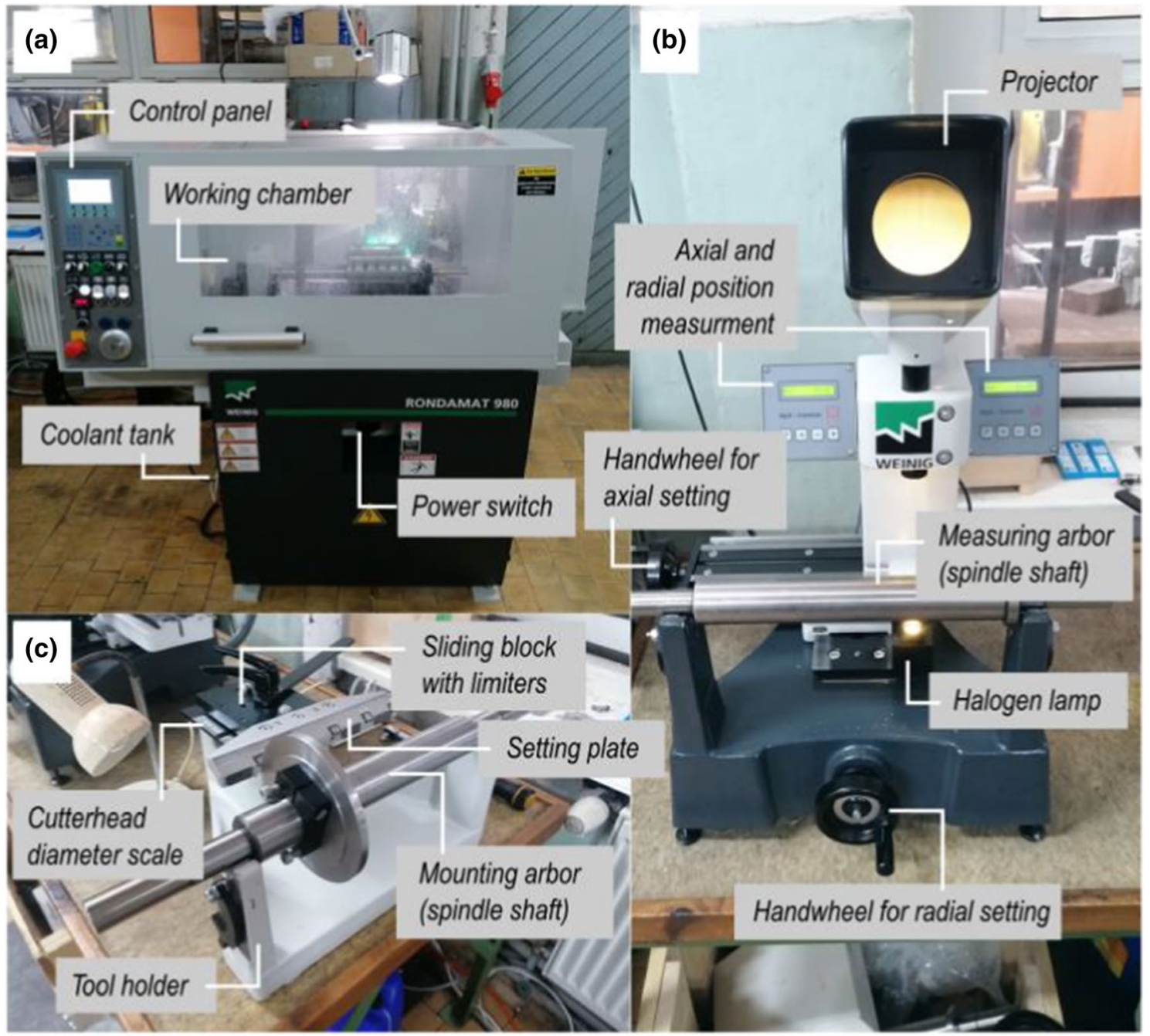

Fig. 1 Grinding station: a Rondamat 980 grinding machine; b OptiControl measuring station; c gauge for setting planer knives in the planer head (all devices produced by Michael Weinig AG, Tauberbischofsheim, Germany) 
Fig. 2 Example of grindingwheel type WI13TM $125 \times 3 \times 4 \times 20$ B 151 V 240 $M$ wet manufactured by DIAMENTPOL S.J. (Katowice, Poland) changes in the geometry of planer knives in the grinding process used in the research program: a general view, $\mathbf{b}$ close-up of the working part of the grinding wheel (CBN abrasive grains and ceramic bond, mag.: $\times 700$ )

Table 1 Technical characteristics of the grinding wheels used in the tests

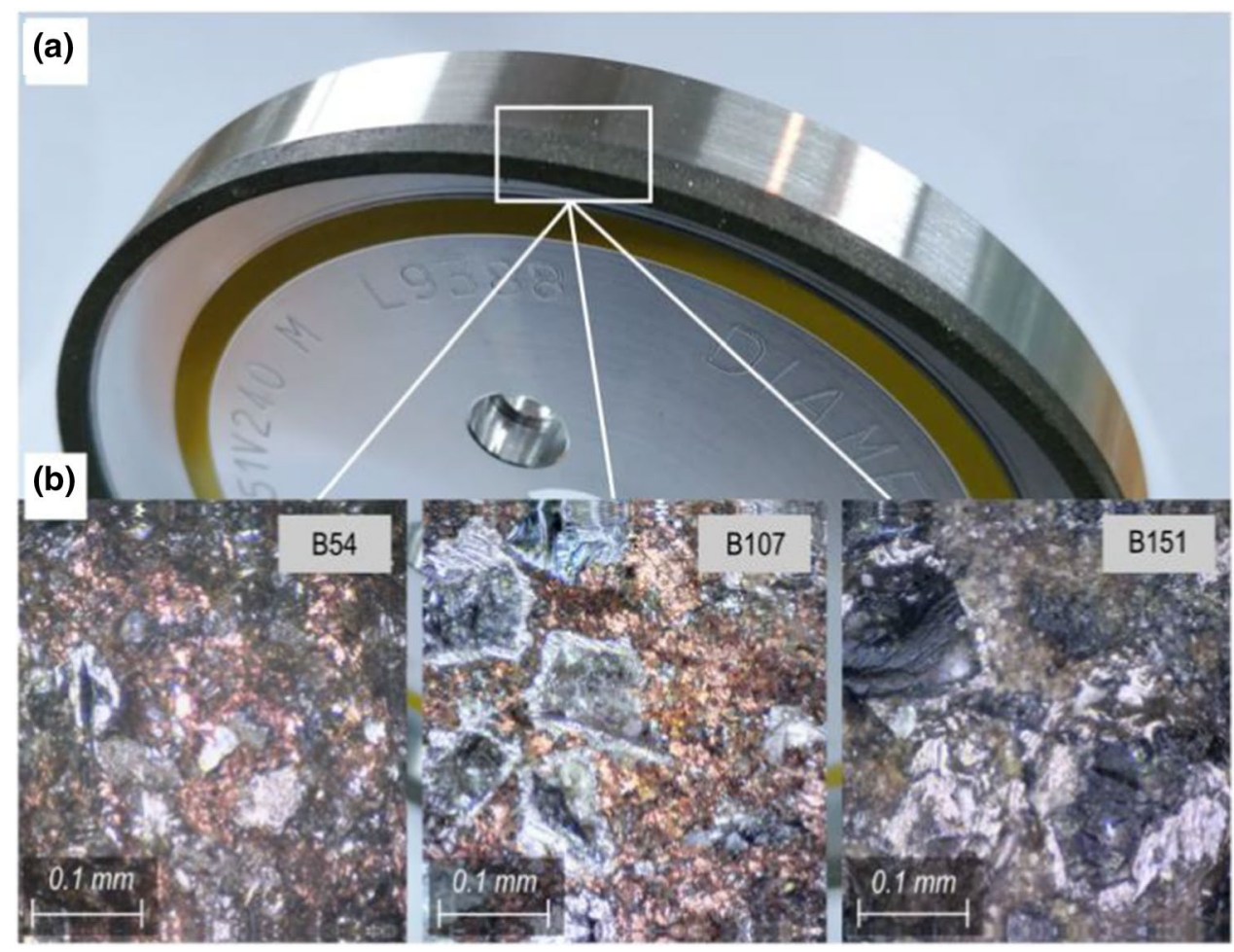

\begin{tabular}{lllll}
\hline Type & Dimensions & $\begin{array}{l}\text { Grain type } \\
\text { and size }\end{array}$ & $\begin{array}{l}\text { Grain size by } \\
\text { FEPA, } \mu \mathrm{m}\end{array}$ & Grain concentration and hardness \\
\hline WI13 & \multirow{2}{*}{$125 \times 3 \times 4 \times 20 \mathrm{~mm}$} & B151 & $150 / 125$ & \multirow{2}{*}{ V240 M } \\
& & B107 & $106 / 90$ & \\
& & B54 & $53 / 45$ & \\
\hline
\end{tabular}

$160 \times 160 \times 50-Z 6$ planer heads, with the grinding operation only being performed on the clearance surface (Fig. 3). The use of a hydro-type mounting and a pressure of $30 \mathrm{MPa}$ ensured the stability and coaxiality of the head mounting on the grinding shaft. As such high pressure causes the internal walls of the hydro-clamping tool to expand, the tool is centred in relation to the machine spindle, free from play. This clamping arrangement ensures a maximum play of $0.005 \mathrm{~mm}$. In practice, this means that all blades will be ground and operate in the same circle.

The methodology of experimental research on grinding planer knives took into account the use of machining parameters that ensure the performance of tests for various loads of abrasive grains in the grinding zone. This goal was achieved using different values of equivalent chip thickness $h_{\text {eq }}$ :

$h_{e q}=\frac{a_{e} \cdot v_{f t}}{v_{s}}, \mathrm{~mm}$.

Assuming the variability of machining parameters, both the variability of the cutting speed ratio $q$ and different values of the specific grinding volumetric efficiency $Z^{\prime}$ were obtained:

$q=\frac{v_{s}}{v_{f t}}$

$Z^{\prime}=a_{e} \cdot v_{f t}, \mathrm{~mm}^{3} \mathrm{~mm}^{-1} \mathrm{~s}^{-1}$

Adopting a sufficiently wide range of values equivalent to the chip thickness $h_{\text {eq }}$ causes the grinding process to be carried out with different forces (normal and tangential), as well as allowing one to compare the machining conditions with its results in the form of assessing the quality of the geometric structure of the surface. This is due to the correlation between the equivalent chip thickness and the arithmetic mean roughness of the surface profile $R a$ :

$R a=C \cdot h_{e q}^{r}, \mu \mathrm{m}$

where $C, r$ is the are constants determined experimentally. 
(a)

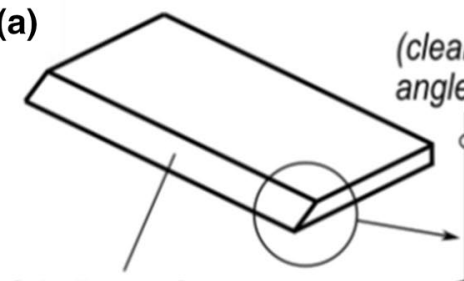

Grinding surface Removed (clearance surf.) material layers (clearance $A_{\gamma}$ (clearance

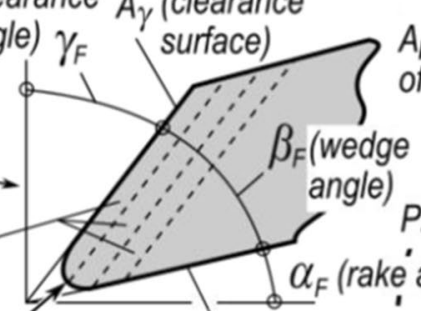

angle)

Planer cutter head

angle)

Cutting edge radius $A_{\alpha}$ (rake surface)

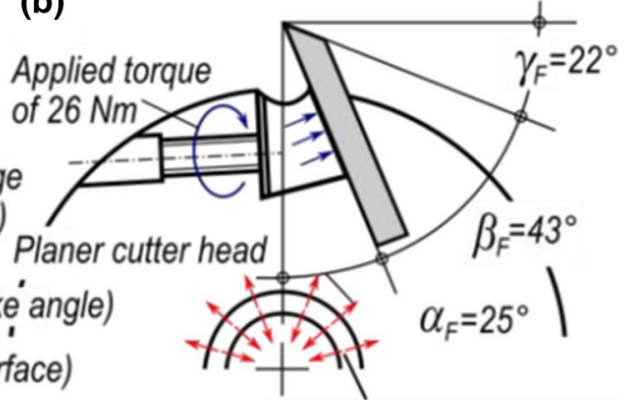

(b)

Pressure (centered and clamped hydraulically)

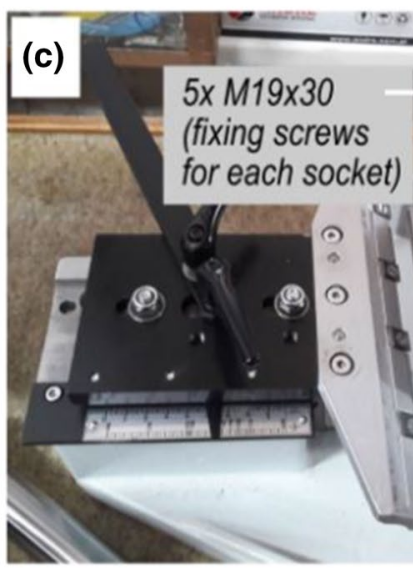

Fig. 3 Knives and their assembly in the planer head: a geometry and angles of the planer knife blade (pictorial diagram, dimensions and scale not maintained); $\mathbf{b}$ diagram of the assembly of knives in the cutting head, $\mathbf{c}$ precise assembly of knives in the cutter head sockets, $\mathbf{d}$ (d)

\section{.}
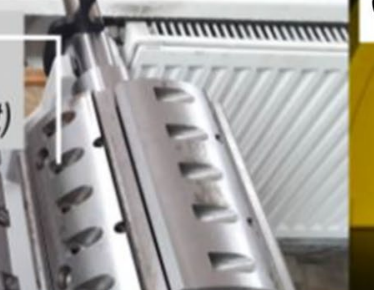

\section{Axis line}

every $0.20 \mathrm{~mm}$
Cutting edge shadow

\section{mag. $20 x$}

Due to the specific nature of the grinding process of planer knife blades, this process possesses different characteristics from the standard processes involved in grinding flat or cylindrical surfaces, for which the cutting speed ratio $q$, expressed as the relation of grinding speed $v_{s}$ to the speed of the workpiece (in this case, the feed rate, $v_{\mathrm{ft}}$ ), usually ranges from 60 to 80 . The variability of technological parameters in the Rondamat 980 grinder allows the use of the speed ratio $q$ in a range from 614 to 43,010 . The maximum value of $q$ was limited to 13896 in the tests. control of the position of knives on the OptiControl measuring station (view of projector screen with radial and axial measuring lines; mag.: 20: 1 , scale division: $0.20 \mathrm{~mm}$ )

The Rondamat 980 grinder allows a wide range of working engagement $a_{\mathrm{e}}$ values from 0.01 to $0.12 \mathrm{~mm}$ for finishing cycles (cycles $1-3$ ) and up to $0.20 \mathrm{~mm}$ for roughing cycles (cycles $4-15$ ). The following $a_{\mathrm{e}}$ values were adopted in the tests: $0.02 ; 0.04 ; 0.08 ; 0.12$ and $0.15 \mathrm{~mm}$. Such a wide range of values resulted from the need to analyze the machining potential of the tested knives for various efficiency of the grinding process. The reference value is a cutting depth equal to $1 / 3$ of the size for superhard grains (Table 2). Usually, exceeding this value causes

Table 2 Comparison of the depth of cut values in relation to the grain size of the grinding wheel

\begin{tabular}{|c|c|c|c|c|c|c|}
\hline & \multicolumn{6}{|c|}{ Depth of cut, $a_{e}(\mathrm{~mm})$} \\
\hline & & 0.02 & 0.04 & 0.08 & 0.12 & 0.15 \\
\hline Grain size & $1 / 3$ of grain size, $\mu \mathrm{m}$ & \multicolumn{5}{|c|}{ Ratio of the depth of cut to $1 / 3$ part of grain size } \\
\hline B151 & 50 & 0.40 & 0.80 & 1.60 & 2.40 & 3.00 \\
\hline B107 & 36 & 0.56 & 1.12 & 2.24 & 3.36 & 4.21 \\
\hline B54 & 18 & 1.11 & 2.22 & 4.44 & 6.67 & 8.33 \\
\hline
\end{tabular}

${ }^{a}$ Stee blue indicates a relatively low ratio $(<2.0)$; orange is a group of values with a large ratio $(>2.0)$, white (no background) is the intermediate value of the ratio 
much faster wear of grains, often leading to rapid wear of the grinding wheel active surface.

The ratio of the depth of cut to $1 / 3$ of the grain size is less than or equal to unity only for small values, i.e. $a_{\mathrm{e}}=0.02$ and $0.04 \mathrm{~mm}$. The research program included the use of the full range of depth of cut values only for the B 151 grinding wheel. The maximum depth of cut value for other abrasive grain sizes is $0.08 \mathrm{~mm}$. This made it possible to carry out tests for different efficiencies in the grinding process and, at the same time, to prevent rapid wear of the grinding wheels' active surface.

The following feed rates $v_{\mathrm{ft}}$ were included in the test program: 130, 473, 700 and $960 \mathrm{~mm} / \mathrm{min}$. On the other hand, the grinding wheel rotational speeds $n_{s}$ were: 1500,3000 , $4600 \mathrm{rpm}$, producing peripheral grinding speeds $v_{\mathrm{s}}$ of $=9.8$, 19.6 and $30.1 \mathrm{~m} / \mathrm{s}$, respectively.

Depending on the selection of the cutting speed ratio $q$ and the depth of cut value $a_{\mathrm{e}}$, the process was carried out with an equivalent chip thickness $h_{\text {eq }}$ from values close to zero $\left(0.0014 \mu \mathrm{m}\right.$ for $a_{\mathrm{e}}=0.02 \mathrm{~mm}$ and $\left.q=13,896\right)$ to $0.24 \mu \mathrm{m}$ (for $a_{\mathrm{e}}=0.15 \mathrm{~mm}$ and $q=614$ ). The actual grinding volumetric efficiency was in the range from 0.04 to 2.40 $\mathrm{mm}^{3} \mathrm{~mm}^{-1} \mathrm{~s}^{-1}$.

The full scope of experimental research resulting from the adopted range of variability of the grinding process parameters is presented in Fig. 4.

The clearance surface of the planer knives needs to be ground until the defects following the wood planing process are eliminated. Therefore, each grinding cycle consisted of programmed passes along the entire length of the blade to level the surfaces and edges of the knives mounted in the planer head seats gradually.

An additional finishing cycle without working engagement was also used in each program, which ensured an additional sparking out pass after the completion of the main machining cycles. The workpiece tangential feed rate in the non-feed cycle is constant for the Rondamat 980 and is $190 \mathrm{~mm} / \mathrm{min}$.

The knife grinding process was conducted with a cooling lubricant (4\% grinding emulsion, obtained from grinding concentrate supplied by Michael Weinig AG, Tauberbischofsheim, Germany). The process of cooling the machining zone, using the flood method, was carried out with the use of two nozzles: lower and upper. The cooling system valves were adjusted in order that the coolant flow constituted 4 LPM (liters per minute).

\subsection{Characterisation of planer knife blades}

In the experimental tests, planer HS Premium knives with a single cutting edge were used, made of high-speed steel (HS6-5-2 steel) with a hardness of $61.9 \pm 0.5 \mathrm{HRC}$, intended for the processing of solid soft wood. In a trial of 11 knives with 3 replicates, hardness was measured by the Rockwell method (indenter: $120^{\circ}$ diamond cone). The chemical composition, typical physical and mechanical properties of High-Speed Steel (material No. 1.3339) according to the EN ISO 4957: 2018 standard are given in Table 3.

${ }^{\mathrm{a}}$ Annealed condition $(+\mathrm{A})$. Hardness in the annealed plus cold drawn condition $(+\mathrm{A}+\mathrm{C})$ may be $50 \mathrm{HBW}$
Fig. 4 Variability of machining conditions assumed in experimental tests on the grinding process of planer knives: a cutting speed and feed rate, b distribution of the value of the equivalent chip thickness depending on the grinding depth, $\mathbf{c}$ distribution of the equivalent value of the chip thickness depending on the ratio of the main speeds process, $\mathbf{d}$ distribution of the values of the specific grinding volumetric efficiency of in relation to the depth of cut (a)

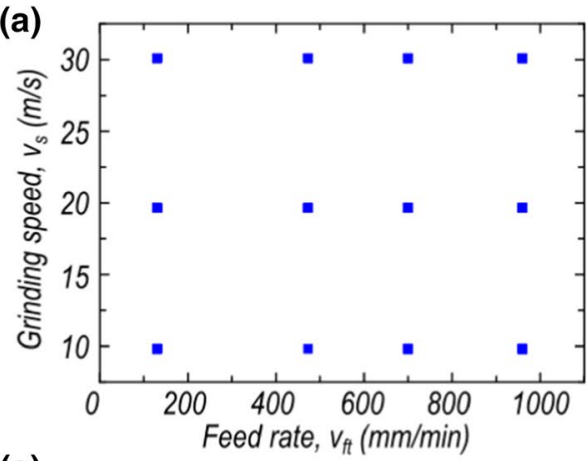

(c)

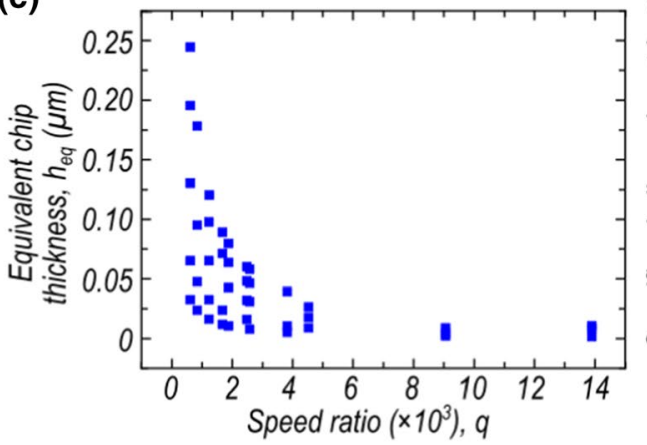

(b)

(d)
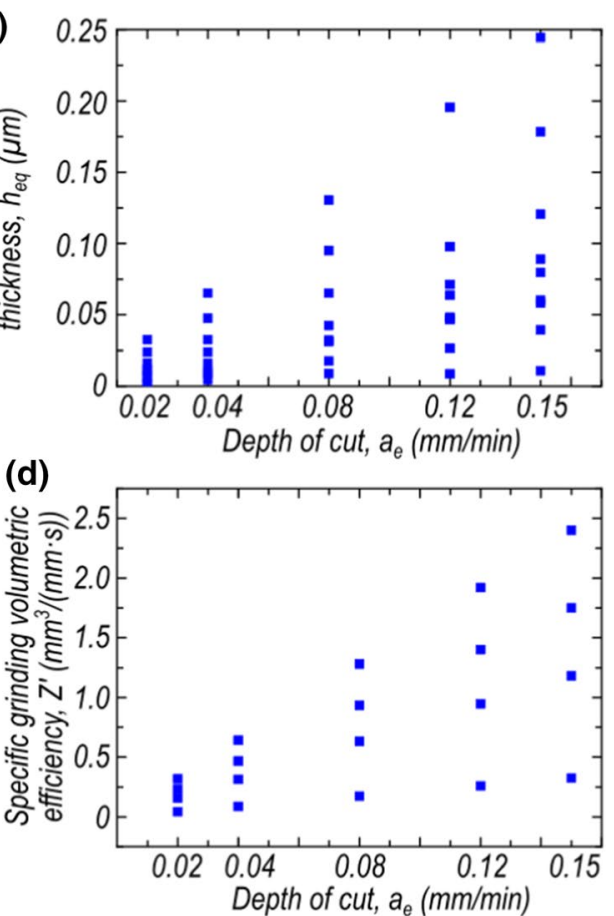
Table 3 Chemical composition, physical and mechanical properties of High-Speed Steel (material No. 1.3339) according to EN ISO 4957: 2018

\begin{tabular}{|c|c|c|c|c|c|c|c|c|c|c|c|}
\hline $\mathrm{C}$ & $\mathrm{Cr}$ & Mn & & Mo & \multicolumn{2}{|c|}{$\mathrm{P}$} & S & $\mathrm{Si}$ & V & & W \\
\hline \multicolumn{12}{|c|}{ Chemical composition (in weight \%) } \\
\hline $0.8-0.88$ & $3.8-4.5$ & \multicolumn{2}{|l|}{$\leq 0.4$} & $4.7-5.2$ & \multicolumn{2}{|c|}{$\leq 0.03$} & $\leq 0.03$ & $\leq 0.45$ & \multicolumn{2}{|c|}{$1.7-2.1$} & $5.9-6.7$ \\
\hline Density, $\mathrm{kg} / \mathrm{dm}^{3}$ & \multicolumn{2}{|c|}{$\begin{array}{l}\text { Modulus of elastic- } \\
\text { ity, GPa }\end{array}$} & \multicolumn{2}{|c|}{$\begin{array}{l}\text { Thermal conductiv- } \\
\text { ity, } \mathrm{W} / \mathrm{m} \cdot{ }^{\circ} \mathrm{C}\end{array}$} & $\begin{array}{l}\text { Specifi } \\
\text { cal res } \\
\mathrm{mm}^{2} / \mathrm{m}\end{array}$ & $\begin{array}{l}\text { electri- } \\
\text { tivity, } \Omega\end{array}$ & Specific therma & capacity & & \multicolumn{2}{|c|}{ Poisson's coefficient } \\
\hline \multicolumn{12}{|c|}{ Physical properties } \\
\hline \multirow[t]{2}{*}{8.12} & $20^{\circ} \mathrm{C}$ & $600^{\circ} \mathrm{C}$ & $20^{\circ} \mathrm{C}$ & $600^{\circ} \mathrm{C}$ & $20^{\circ} \mathrm{C}$ & $600^{\circ} \mathrm{C}$ & 412 & & & 113 & \\
\hline & 224 & 180 & 27.6 & 26.1 & 0.524 & 1.04 & & & & & \\
\hline \multicolumn{3}{|l|}{ Hardness } & \multirow[t]{2}{*}{ Yield, MP } & \multirow{2}{*}{\multicolumn{2}{|c|}{ Tensile, MPa }} & \multirow[t]{2}{*}{ Impact, J } & \multirow[t]{2}{*}{ Elongation, \% } & \multicolumn{4}{|c|}{ Reduction in cross section on fracture, $\%$} \\
\hline Brinell $(\mathrm{HBW})^{\mathrm{a}}$ & \multicolumn{2}{|c|}{ Rockwell (HRC) } & & & & & & & & & \\
\hline \multicolumn{12}{|c|}{ Mechanical properties } \\
\hline$\leq 262$ & $\geq 64$ & & $\geq 215$ & $\geq 451$ & & 42 & 32 & 21 & & & \\
\hline
\end{tabular}

and hardness in the annealed plus cold rolled condition $(+\mathrm{A}+\mathrm{CR})$ may be $70 \mathrm{HBW}$ higher than in the annealed condition $(+\mathrm{A})$

The sets of knives with the dimensions $160 \times 30 \times 3 \mathrm{~mm}$ were manufactured at Leitz GmbH \& Co. KG (Germany). The geometrical features of the used planing blades are as follows: contour rake (cutting) angle $\alpha_{\mathrm{F}}=25^{\circ}$, contour clearance angle $\gamma_{\mathrm{F}}=22^{\circ}$ and contour wedge angle $\beta_{\mathrm{F}}=43^{\circ}$.

Microscopic analysis showed that the factory-sharpened knives are characterized by high surface directionality. These knives are sharpened in a different kinematic system than that provided by the Rondamat 980 grinding system. During the production process, the knives are sharpened during longitudinal peripheral grinding of the surface, which is reflected in the form of almost perpendicular ( $L)$ machining marks on the relief surface relative to the cutting edge (Fig. 5). The angle of the rectilinear machining marks, with a transverse pitch equal to $0.2 \mathrm{~mm}$, ranged from $82^{\circ}$ to $84^{\circ}$.

The analysis of the surface topography of the planer knives shaped in the production process by Leitz $\mathrm{GmbH}$ $\&$ Co. KG allowed one to establish reference values for the conducted research, the results of which are presented in the "Results and discussion" section. The assessment of the surface morphology and the measurement of roughness and waviness parameters were carried out in accordance with the methodology described below.

\subsection{Methodology for observing and measuring surface texture}

The operational properties of the surface, i.e. the friction coefficient, abrasion resistance, fatigue strength (which decreases with increasing roughness), depend on the size and shape of the roughness. Similarly, waviness affects the wear intensity of the rubbing surfaces. In the event of abrasive wear, waviness increases the amount of abrasive material and thus accelerates the wear process. On the other hand, in the case of adhesive wear, waviness allows one to work with higher surface pressures and reduces wear [23].

To characterize the surface topography of planer knives, a set of selected SGP parameters was used, which were determined on the basis of measuring the surface with a size of $3.8 \times 4.0 \mathrm{~mm}$ and with a resolution of $2 \mu \mathrm{m}$ in the direction transverse to the machining marks, as well as a pitch of $15 \mu \mathrm{m}$ between the profiles. In this way, information on the micro-unevenness of the ground surface was obtained from 610221 measurement points (321 profiles of 1901 points). The movement of the measuring head was carried out at a speed of $500 \mu \mathrm{m} / \mathrm{s}$, which resulted in the measurement time of $15.2 \mathrm{~mm}^{2}$, equal to $52 \mathrm{~min}$ and $28 \mathrm{~s}$.

Surface geometric microstructure measurements were made with use of a TalySurf CLI2000 optical profilometer by Taylor Hobson Ltd. (Leicester, UK) and Taly Map Silver 4.1 software with Mountains Technology ${ }^{\mathrm{TM}}$ (Digital Surf, Besançon, France). The profilometer was equipped with LK-031 optical displacement sensor (wavelength: $670 \mathrm{~nm}$, power: $0.95 \mathrm{~mW}$, spot diameter: approx. $30 \mu \mathrm{m}$, resolution: $1 \mu \mathrm{m})$ and LK-2001 controller (Keyence, Osaka, Japan). The geometric structure of the ground surface (relief surface) was assessed mainly by means of a set of surface parameters of roughness and waviness, such as: $\mathrm{Sa}$ is the arithmetic mean deviation of the surface roughness (mean of the absolute values of the surface departures above and below the mean plane within the sampling area for roughness component of surface texture); St is the total height of the surface (height between the highest peak and the deepest valley within the sampling area for the roughness component of the surface texture); Sds is the density of summits (peaks) of the surface (defines the number of summits of a unit sampling area for roughness component of surface texture); Wa is the 

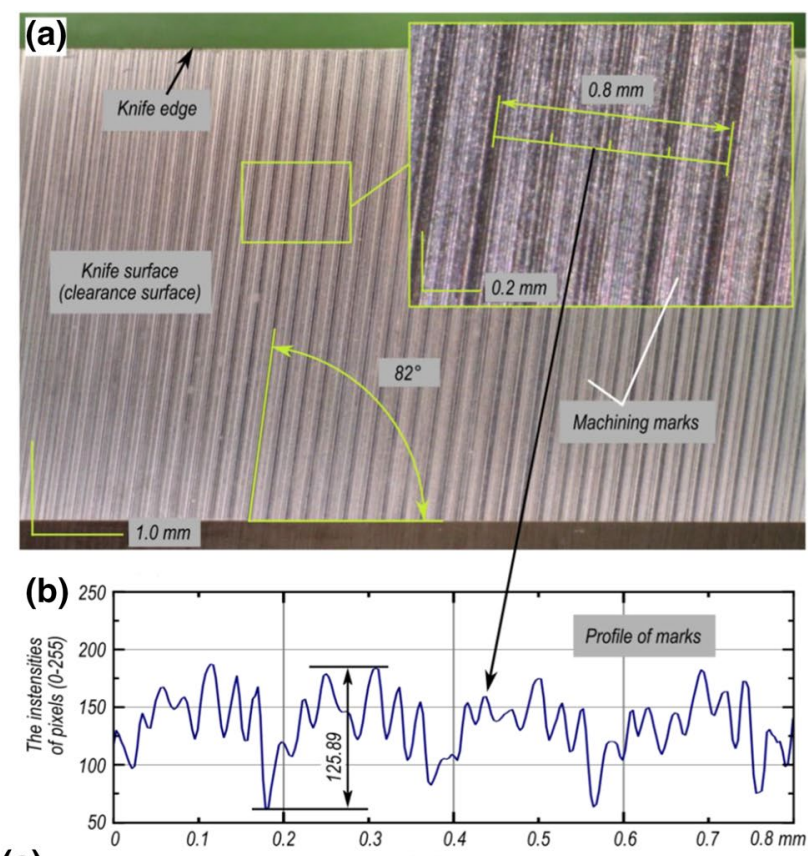

(c)

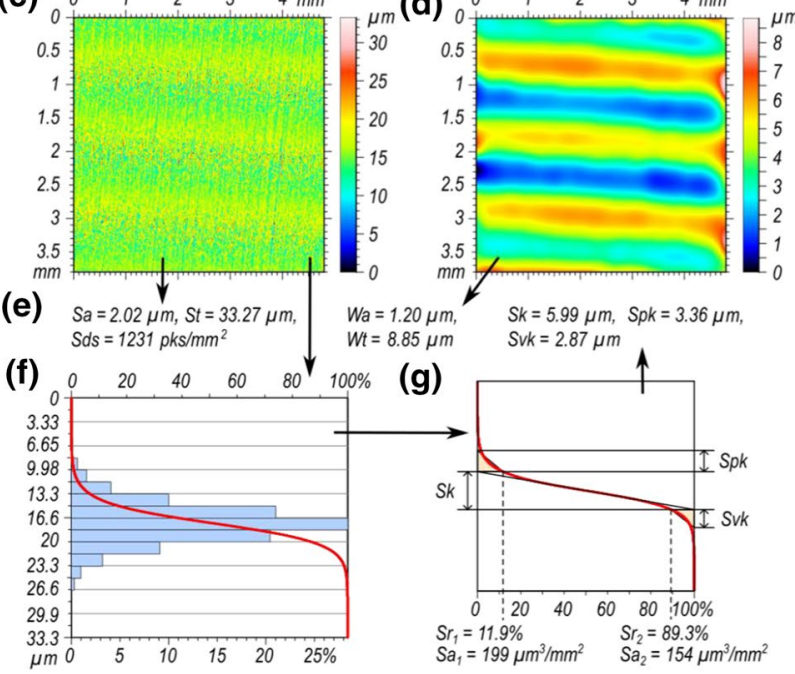

Fig. 5 Morphological characteristics of the relief surface of planer knives formed in the production process by Leitz GmbH \& Co. KG: a microscopic image of the surface (over $\times 50$ ), $\mathbf{b}$ the intensities of pixels along a $0.5-\mathrm{mm}$-long line across the machining marks, $\mathbf{c}$ surface roughness, d surface waviness, e amplitude, spatial and functional parameters calculated on the surface, $\mathbf{f}$ Abbott-Firestone curve study, g graphical study of Sk parameters (Gaussian Filter: $0.8 \mathrm{~mm}$ )

arithmetical mean height of surface waviness (defined like Sa but for the waviness component of the surface texture); $\mathrm{Wt}$ is the total height of surface (defined like St but for the waviness component of the surface texture).

Optical profilometry measurements were supplemented with microscopic observations of the state of the ground surface. In this case, a high-resolution digital microscope, namely a Dino-Lite Edge AM7915MZT (Electronics Corp., New Taipei City, Taiwan), was used. Using a 5-megapixel matrix CMOS detector, images with a resolution of $2592 \times 1944$ pixels and a magnification of up to $220 \times$ were acquired after the grinding process. Acquisition and image pre-processing was carried out using dedicated DinoCapture software (rev. 1.5.39.C, by AnMo Electronic Corporation) with additional systems: flexible control of illumination intensity (FLC), Extended Depth of Field (EDOF), Extended Dynamic Range (EDR).

Primary analyses of surface images were performed using ImageJ software (ver. 1.53i) developed at the National Institutes of Health and the Laboratory for Optical and Computational Instrumentation (LOCI, University of Wisconsin, USA).

Research was focused on identification of surface isotropy, analyses of machining traces and the detection of microstructural surface defects, such as micro-cracks, chipping, bursting, abrasive wear, indentations or scratches. The evaluation of surface quality and identification of any defects on abrasive-treated areas can be carried out by various methods, including image processing [24]. In this case, universal filtering algorithms were applied to the processed surface image to separate the straight lines contained in the image from the background.

\section{Results and discussion}

\subsection{Characteristics of clearance surface of planer knives}

The structure of the shaped surfaces in the grinding process results from the kinematics of the machining process and the relative position of the grinding wheel in relation to the displaced planer knife embedded in the planer head seat.

The SGP structure of knives, shaped in the manufacturing and grinding process, is characterized by a specific orientation.

The occurrence of surface irregularities can constitute a beneficial aspect for the planing process, e.g. with regard to the cutting process, serrated knives (blades) are often used. This is due to the fact that in the work of a knife, the main purpose is to break the bonds that are responsible for maintaining the integrity of the structure of the material being processed. The cutting process may consist of two types of basic movements: the slice-similar to the work of a saw, and the push-analogous to the work of an ax. In practice, both movements occur simultaneously in different proportions.

Each smooth blade is in fact uneven on a microscale, as can be seen in Fig. 6 in the form of an unevenness of the order of a few $\mu \mathrm{m}$. The presence of micro-unevenness on the cutting edge (or micro-serrations) can be a significant factor in increasing the frictional force between the blade 


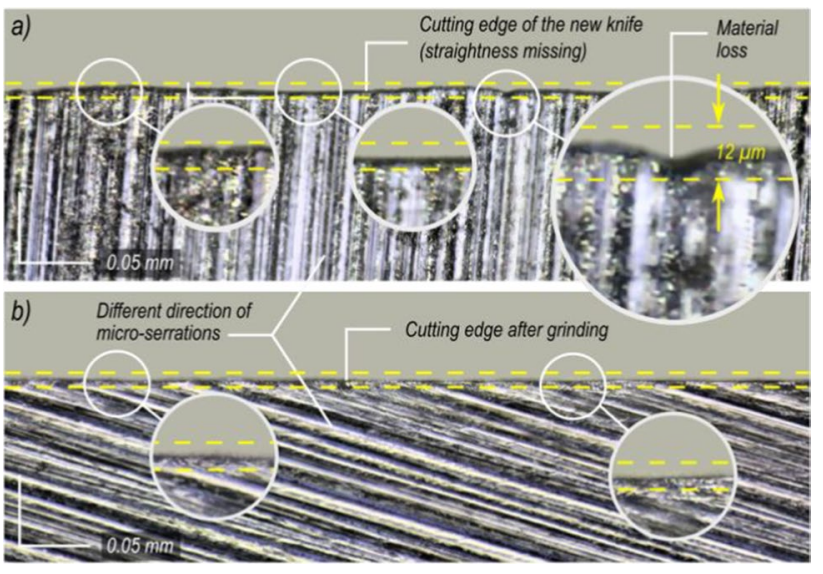

Fig. 6 Cutting edge of the Leitz HS Premium planer knife (magnification $\times 700)$ : a knife sharpened at the factory, $\mathbf{b}$ knife sharpened with the Rondamat 980

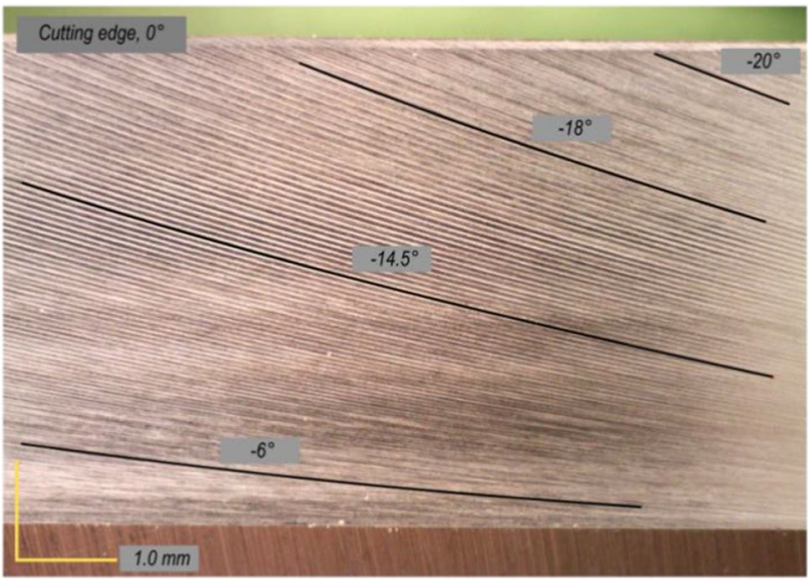

Fig. 7 Microscopic photo of the relief surface of planer knives, shaped in the grinding process in Rondamat 980 kinematics (over $\times 50)$; grinding parameters: $a_{\mathrm{e}}=0.02 \mathrm{~mm}, v_{\mathrm{ft}}=960 \mathrm{~mm} / \mathrm{min}$, $v_{\mathrm{s}}=4600 \mathrm{rpm}$

and the material being cut, thereby increasing the aggression of the cutting process and thus the work efficiency. Giovannini et al. showed that the introduction of micro-serrated geometry to a surgical blade lengthens the cutting edge and reduces the force necessary to perform the cutting operation, especially at speeds from 5 to $20 \mathrm{~mm} / \mathrm{s}$ [25]. As a result, the loss of cut material increases and the incision deepens.

Machining marks on knives ground in experimental tests have a variable arrangement angle with respect to the cutting edge, a phenomenon which can be seen in Fig. 7. These marks are not rectilinear and go from being parallel (at an angle close to $0^{\circ}$ ) to more and more inclined, aiming to create a surface with radial directionality, resulting from the radius of the grinding wheel. The angle of the machining marks close to the cutting edge is about $20^{\circ}$.
The variable curvature of the machining marks results from the relationship between the direction and speed of the grinding surface and the rotating grinding wheel in the Rondamat 980 grinder. Figure 8 shows the test result in which the grinding wheel, moving from the right-hand side, performs a grinding operation with a depth of cut equal to $0.04 \mathrm{~mm}$. At a distance of $80 \mathrm{~mm}$ of the measured profile, the stopping point of the grinding wheel is clearly revealed, which is manifested by a height error. Surface fragments were examined using the optical method. By combining microscopic images, a clear trace (about $2 \mathrm{~mm}$ wide and $26 \mathrm{~mm}$ long) of the grinding wheel active surface, recessed into the processed material, was obtained.

Reference to the characteristics of the geometric structure of the surface in relation to its performance, including the friction coefficient under lubrication and dry conditions, can be found, inter alia, in the study [26] — Fig. 9.

From the analyses presented by the authors, it can be concluded that deformation (hysteresis) is the dominant friction mechanism, as the value of this factor is much higher than the friction associated with adhesion. Friction is highest for a directed structure, loaded in the direction perpendicular to the machining marks, and decreases for subsequent structures, reaching the lowest value for surfaces with a high degree of isotropy.

The results of these studies can be related to the analysis of the geometrical structure of planer knives, the relief surface of which, depending on the adopted machining parameters, is characterized by distinct unidirectional grinding marks. The machining marks are inclined in relation to the cutting edge, and thus in relation to the direction of the knives in the planing process. This means that the main part will be taken by processes taking place perpendicular to the micro-unevenness of the surface, while the average friction coefficient will be high.

Based on the analysis of the surface image of the knives after the grinding process (Fig. 10), one may draw conclusions concerning the density and height of the roughness generated by different grain sizes.

The analysis uses a two-dimensional graph of the intensities of pixels along a line within the image, as well as roughness profiles. The profile defined from the $x$-axis image represents distance along a line $0.5 \mathrm{~mm}$ long, while the $y$-axis is the pixel intensity (in 0-255 scale for an 8-bit image). The analysis of the surface topography consisted of the single profile extraction form surface and the use the roughness and waviness motifs method according to ISO 12085. Both the image analysis and the roughness profile analysis reveal a difference in the height and width of the machining marks obtained in the grinding operation with grinding wheels of various grain sizes. The impact of the grinding process parameters on the load-bearing area is described in a later section of this article. 
(a)

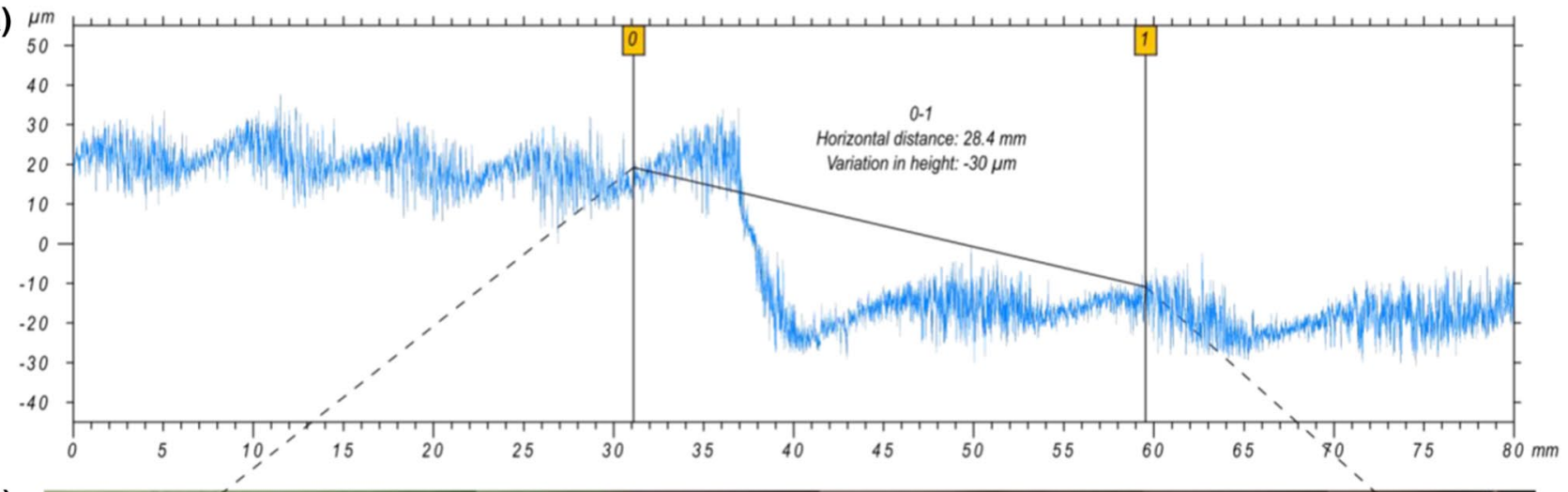

(b)

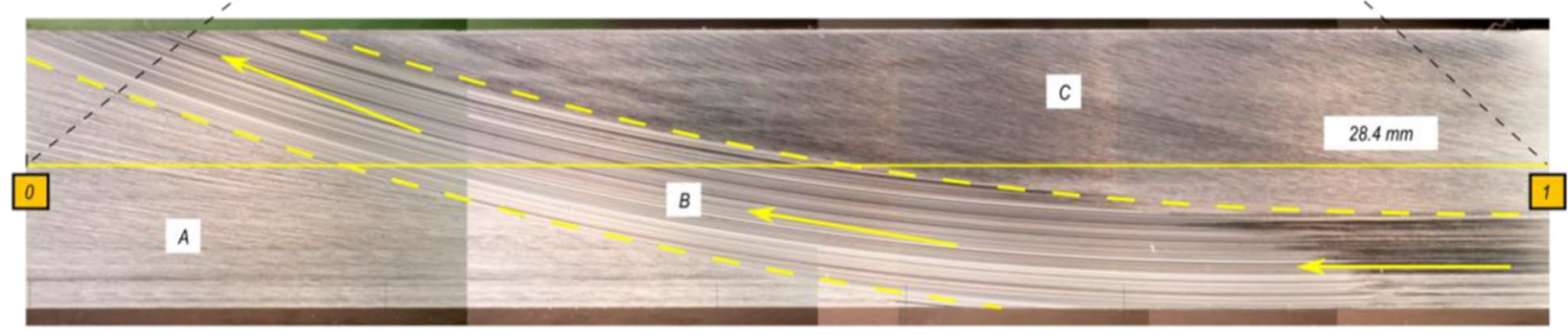

Fig. 8 Character of surface at point of contact of grinding wheel with material removed in Rondamat 980 kinematics: a surface profile along a length of $80 \mathrm{~mm}$; $\mathbf{b}$ a series of combined microscopic photos (over $\times 50)$ showing a fragment of the surface with visible zones:

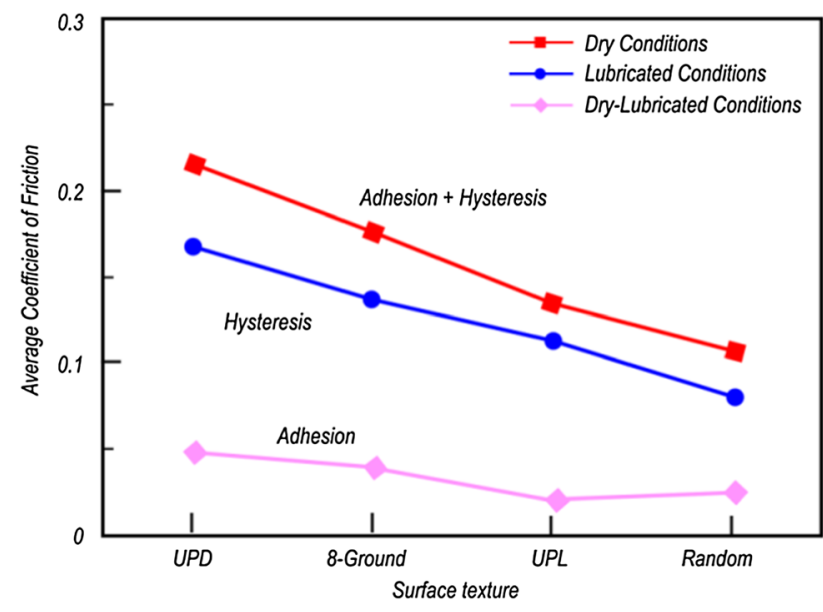

Fig. 9 Variability of the friction coefficient components in relation to the nature of the geometric structure of ground and polished surfaces [26]: $U P D$ directed surface, action perpendicular to the direction of machining traces; $U P L$ directed surface, action parallel to the direction of machining traces, 8 -ground surface ground along a figure-ofeight-shaped path, Random highly isotropic surface

The depth of the grooves is greater for B54 and B107 grains than for B151 grains. In the case of smaller grains, the variability of the gray intensity of pixels exceeds 150 [in range from 0 (black) to 255 (white)], while the maximum depth of motifs $(R x)$ is over $20 \mu \mathrm{m}$. For valleys
(A) before contact with the wheel, (B) in contact with the wheel, and (C) after the wheel has passed; grinding parameters: $a_{\mathrm{e}}=0.04 \mathrm{~mm}$, $v_{\mathrm{ft}}=960 \mathrm{~mm} / \mathrm{min}, v_{\mathrm{s}}=1500 \mathrm{rpm}$

resulting from B151 abrasive grinding, the depth of roughness motifs is significantly reduced $(R x=13.3 \mu \mathrm{m})$.

A graphical study of parameters from the $R k$ group (ISO 13565-2 standard) provides one with additional information contained in the bearing ratio curve (Abbott-Firestone Curve) and information related to potential abrasive wear of surfaces during the operational process.

For a B54 grinding wheel, the surface profile is characterized by a relatively even proportion of peaks and valleys. In the case of a B107 grinding wheel, we note that the proportion of load-bearing valleys in the profile increased at the expense of the proportion of peaks, along with the highest value of reduced valley depth. The analyzed surface possesses the greatest potential in terms of abrasion resistance and maintenance of the lubricating oil film. The surface obtained after the grinding process with a grinding wheel with B151 grains has a relatively larger proportion of the load-bearing peaks above the roughness core profile. This means that this surface may have a slightly greater initial resistance than the other surfaces.

The above results show that the use of CBN grains of different sizes during the grinding process shapes surfaces with a different morphology, which may translate into different exposure to tribological phenomena, mainly friction phenomena, which will result in a different service life of these surfaces. 
(a)

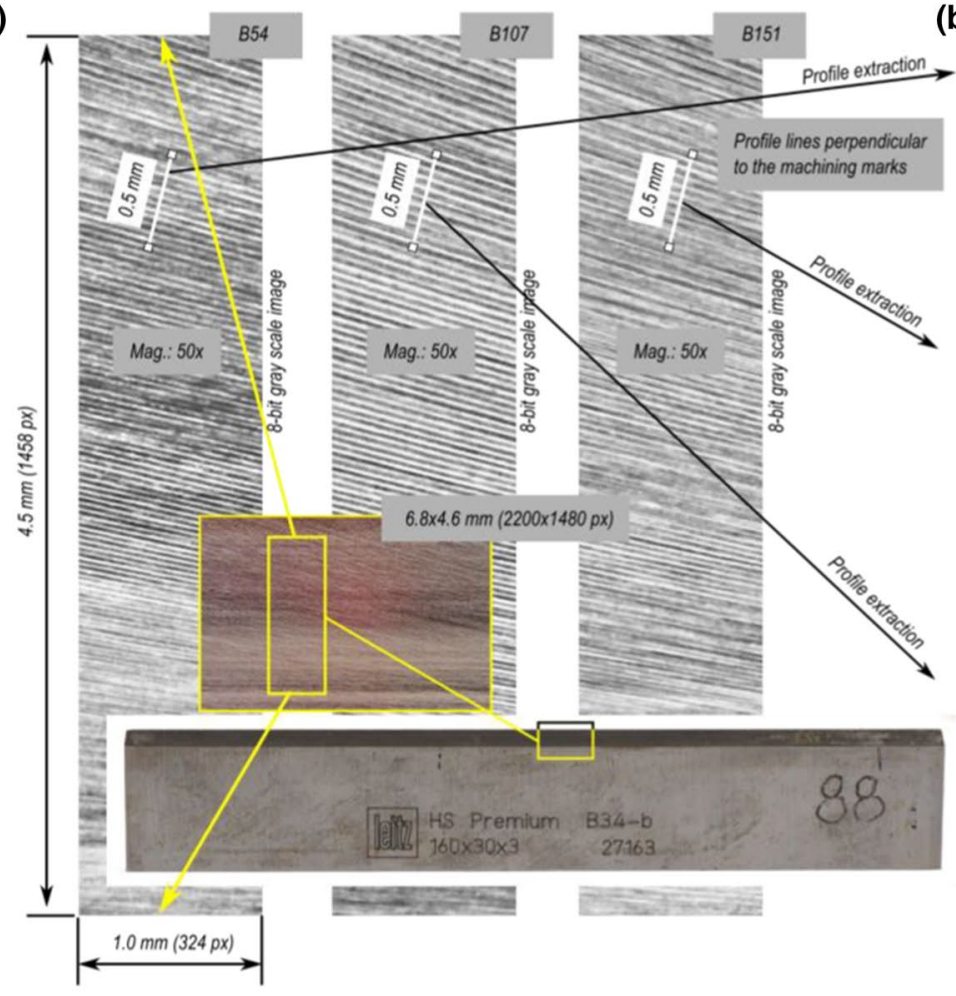

(b)
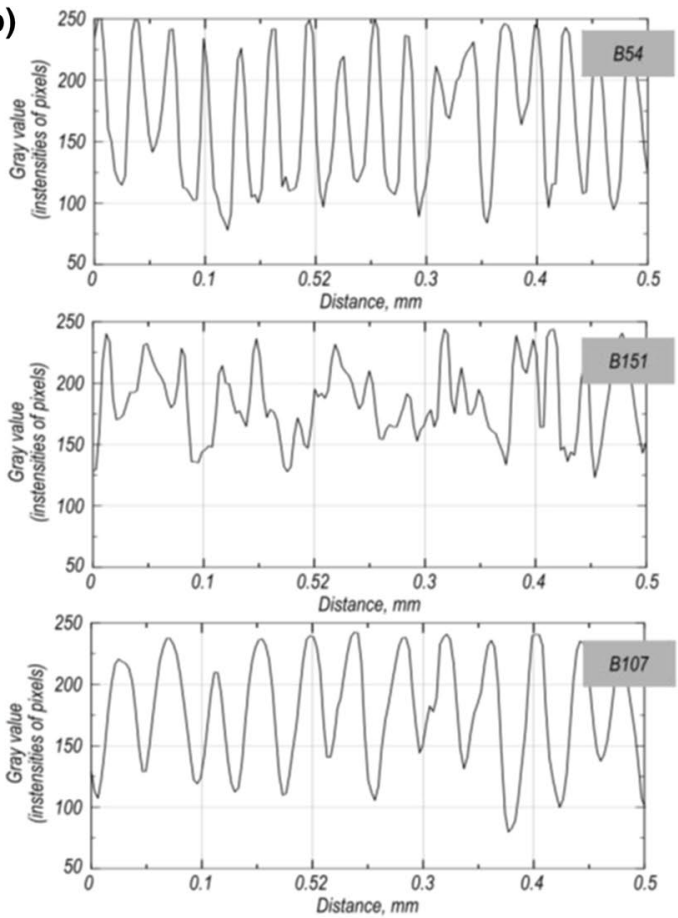

(c)
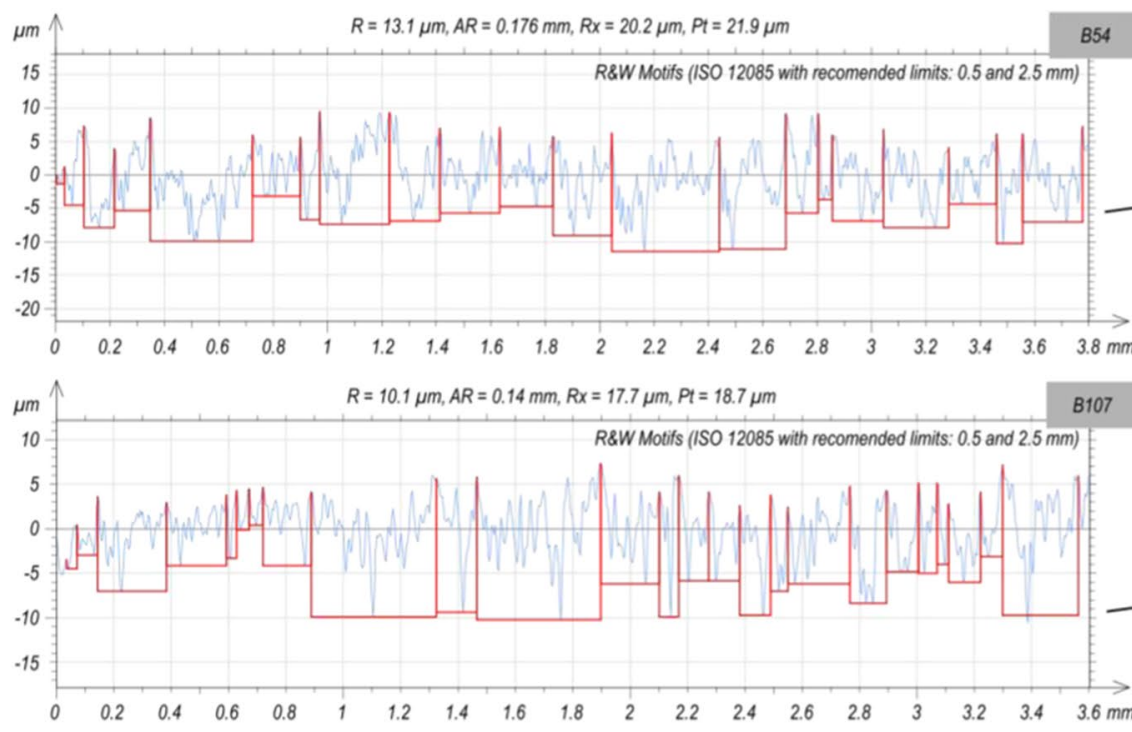
B107

(d)
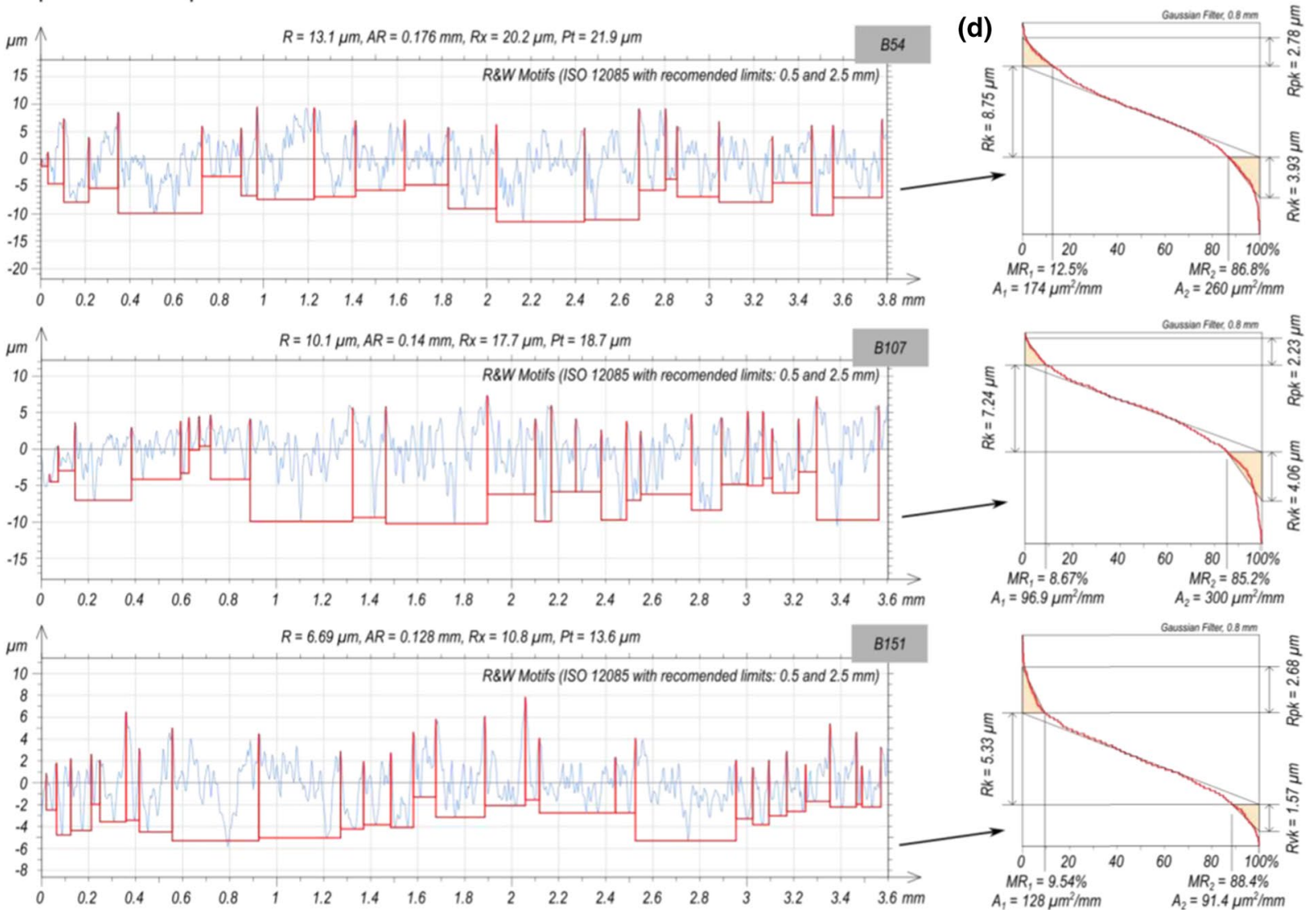

$B 151$

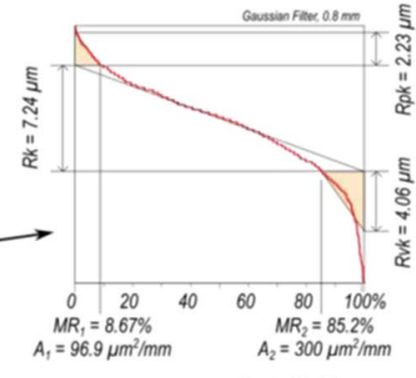

$M R_{1}=8.67 \%$
$A_{1}=96.9 \mu \mathrm{m}^{2} / \mathrm{mm}$

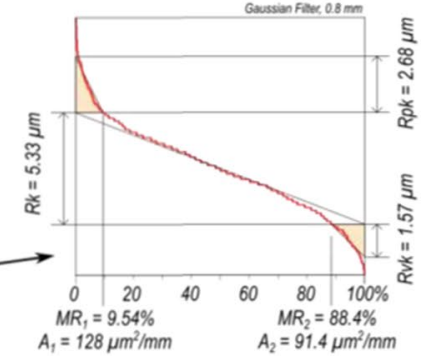

Fig. 10 Characteristics of the surface structures of the knife contact surfaces obtained with the use of various abrasive grain sizes (machining parameters: $a_{\mathrm{e}}=0.02 \mathrm{~mm}, v_{\mathrm{ft}}=473 \mathrm{~mm} / \mathrm{min}$, $n_{\mathrm{s}}=4600 \mathrm{rpm}$ ): a surfaces with clearly visible micro-grooves (area $50 \times$; figure presents knife with marked area of analysis - from the middle area of $6.8 \times 4.6 \mathrm{~mm}$ an area of interest of $4.5 \times 1.0 \mathrm{~mm}$ was extracted) b intensities of pixels along a 0.5 -mm-long line across machining marks, $\mathbf{c}$ exemplary profiles with Roughness \& Waviness Motifs parameters, $\mathbf{d} R k$ parameters for measured surfaces 
The difference in the kinematics of the grinding process of the planer knife blade is significant, and is also due to the less favorable chip removal conditions and the formation of a burr on the knife edge in the case of the front surface grinding of the Rondamat 980 grinder. The grinding process should be supplemented with a burr removal operation (Fig. 11).

\subsection{Surface defects after grinding}

An important aspect that defines the proper conditions for the grinding process of planer knives are defects arising on a machined surface as a result of the interaction of the grinding wheel active surface on the material in the contact zone. The thermal effect may be of particular importance here, as it affects the structure of the material and its operational properties. Due to the fact that the grinding process concerns surfaces with a variable cross-section (the height tends towards zero in the direction of the cutting edge), this aspect is of key importance.

Figure 12 shows examples of surfaces with defects. As a result of the research program, two types of surface defects shaped in the grinding process were observed:

- grooves or scratches-surface damage caused by the movement of an abrasive grain, pressed into the surface of the material;

- grinding burns - a color change on the material surface due to the formation of an oxide film. This defect is considered to be one of the most dangerous and disqualifies the manufactured product. It is associated with local heating of the surface layer of the object to a temperature above the austenitic transformation and the formation of a layer of an undetermined martensite. As a result, both the hardness and abrasion resistance of the surface layer decrease, while the martensite breaks down into a pearlitic structure, which becomes dark in color [27].

An optical analysis covered an area of approximately 30 $\mathrm{mm}^{2}(6.8 \times 4.5 \mathrm{~mm})$ of the central section of the clearance surface of the knife. The use of binarization with a constant threshold, equal to 0.35 , allowed one to determine the differences between the surface quality, which was assessed using the $Q_{\mathrm{BL}}$ index:

$Q_{B L}=\frac{1}{n} \sum_{i=1}^{n} b_{i}$,

where $b$ signifies pixels marked as active after binarization (marked with a binary value of 0 ), and $n$ is the number of analyzed pixels.
This index allows one to quantify the level of surface defectiveness, distinguishing sites of burns, grooves and scratches on it based on their color. The reference value for the $Q_{\mathrm{BL}}$ index was the result obtained for the surface of a new knife, manufactured and sharpened by Leitz $\mathrm{GmbH}$ \& Co. KG. The index value for the clearance surface of the knife was 0.01675 .

Therefore, it was assumed that surfaces with a $Q_{\mathrm{BL}}$ index lower than 0.02 (the established limit value) would be classified as surfaces without grinding defects.

Depending on the machining parameters (grain size, depth of cut, feed rate and rotational speed of the grinding wheel), the grinding process resulted in surfaces with different characteristics, and thus with a different $Q_{\mathrm{BL}}$ index value. Data analysis has shown that regardless of the abrasive grain size used, surfaces can be obtained with no, or at most a marginal number of grinding defects on the treated surface. In total, about $44 \%$ of the samples had a $Q_{\mathrm{BL}}$ index lower than 0.02 (2\%). In this group, B54 grains constitute 11 cases, B107-12, and B151-14 cases. The analysis did not reveal any clear influence of the abrasive grain size on the intensity of the occurrence of thermal defects on the machined surface, with a slight tendency indicating larger grains as being more favorable.

The comparison of the $Q_{\mathrm{BL}}$ index values with the applied machining parameters showed that the depth of cut $a_{\mathrm{e}}$ did not have a statistically significant influence on the quality of the shaped surface. However, to avoid surface defects after machining, it is preferable to use a high or very high feed rate $v_{\mathrm{ft}}$, thereby reducing the contact length of the wheel with the workpiece in the grinding cycle. Thus, it places under discussion the grinding practice of grinding planer knives only with a low value of specific grinding volumetric efficiency.

An example of the effect of changing the feed rate on the microstructure of the surface shaped in the grinding process is shown in Fig. 13. This image clearly shows the densely arranged machining marks in the form of transverse grooves and scratches on the entire surface. To enhance the described surface features, part of the image was converted to black and white and a thresholding operation was carried out to filter out less important features. Additionally, on the right-hand side of each image there is an enlargement of a fragment of the analyzed area.

In the case of the lowest feed rate used $(130 \mathrm{~mm} / \mathrm{min}-$ Fig. 13a), despite the use of intensive flood cooling, a dark longitudinal mark can be seen in the lower part of the image, indicating a surface burn. Increasing the feed rate (up to $473 \mathrm{~mm} / \mathrm{min}$-Fig. 13b) changed the operating conditions of the abrasive grains and the surface quality after machining. For the average feed rate, a more even pattern of machining marks was obtained-more diagonal grooves (scratches) formed by the removal of material by active 

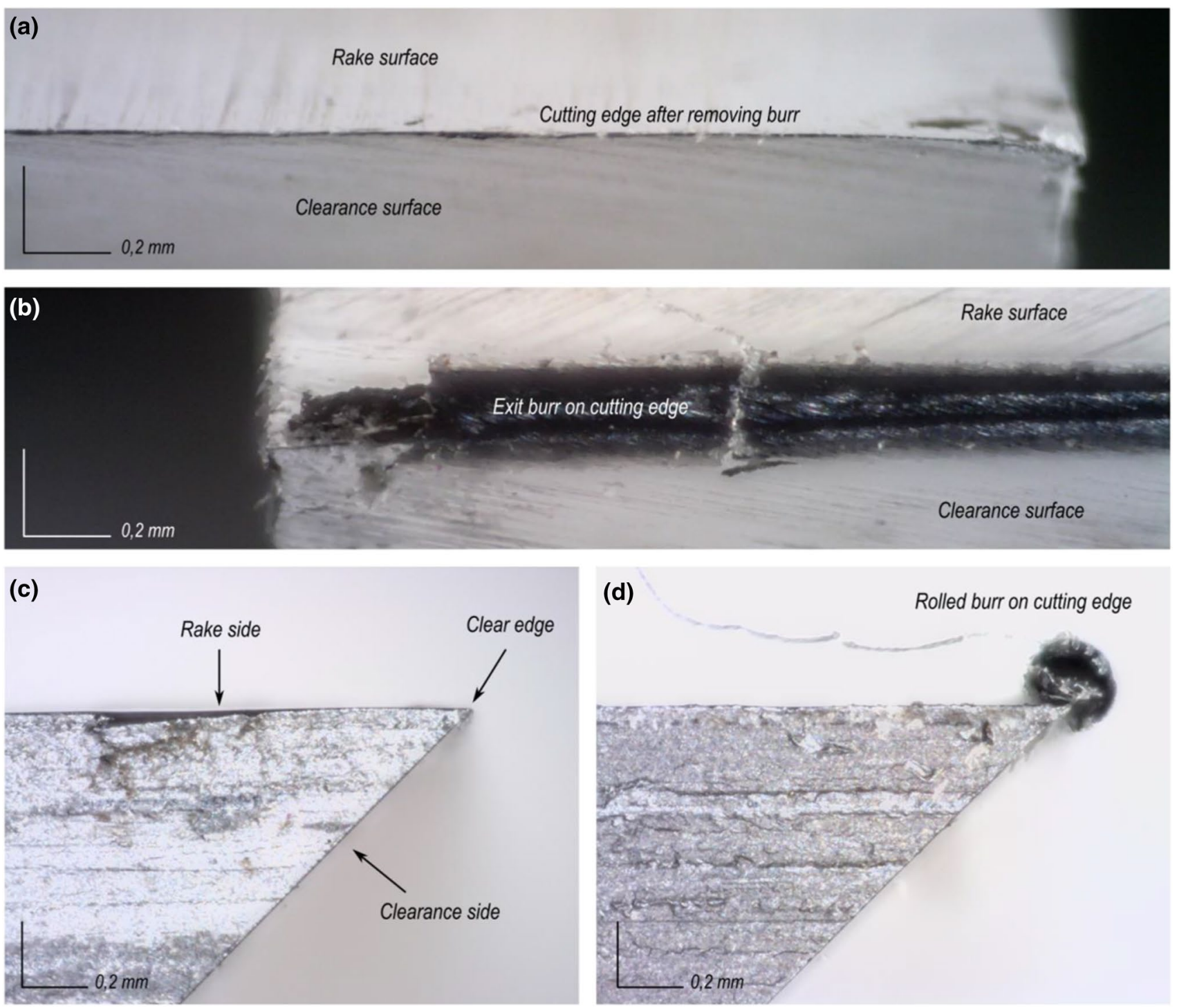

Fig. 11 The burr generated on the cutting edge of planer knives as a result of the grinding operation in the Rondamat 980 kinematics: a edge after deburring operation (over $\times 150)$; $\mathbf{b}$ edge with visible burr (over $\times 150)$; $\mathbf{c}, \mathbf{d}$ view from the side to the edges (over $\times 200)$

abrasive grains are visible on the surface. Dark surface discoloration was not observed. On the other hand, the use of a high feed rate $(960 \mathrm{~mm} / \mathrm{min}-$ Fig. 13c) resulted in the removal of more material. At the same time, the contact of the grinding wheel active surface with the workpiece surface was even shorter, which simultaneously reduced the duration of thermal impact in the machining zone. Due to the dynamics of the micro-cutting process, the values of the equivalent chip thickness $\left(h_{\text {eq }}\right)$ and the specific grinding volumetric efficiency $\left(Z^{\prime}\right)$ increased. Under these conditions, the obtained surfaces are characterized by a very clear orientation and deep machining marks, which give the surface the character of micro-serrated blade geometry.

The research also included the analysis of the grinding process at a variable speed of grinding wheel rotation.
As a result of experimentation and surface evaluation, it has been shown that low or medium speed of the grinding wheel spindle may be advantageous. Rotations typically used in the industry (4600 rpm) usually had a negative impact on the number of observable defects on the surface assessed after the grinding process. Interestingly, grinding machines are often not equipped with a speed control mechanism for the grinding wheel spindle. This is also the case with the Rondamat 980 grinder currently available on the market.

Figure 14 summarizes the contour plots (with interpolation of intermediate data between measurement points) which reveal the impact of individual grinding process parameters on the $Q_{\mathrm{BL}}$ index. In the graphs, a dashed line 

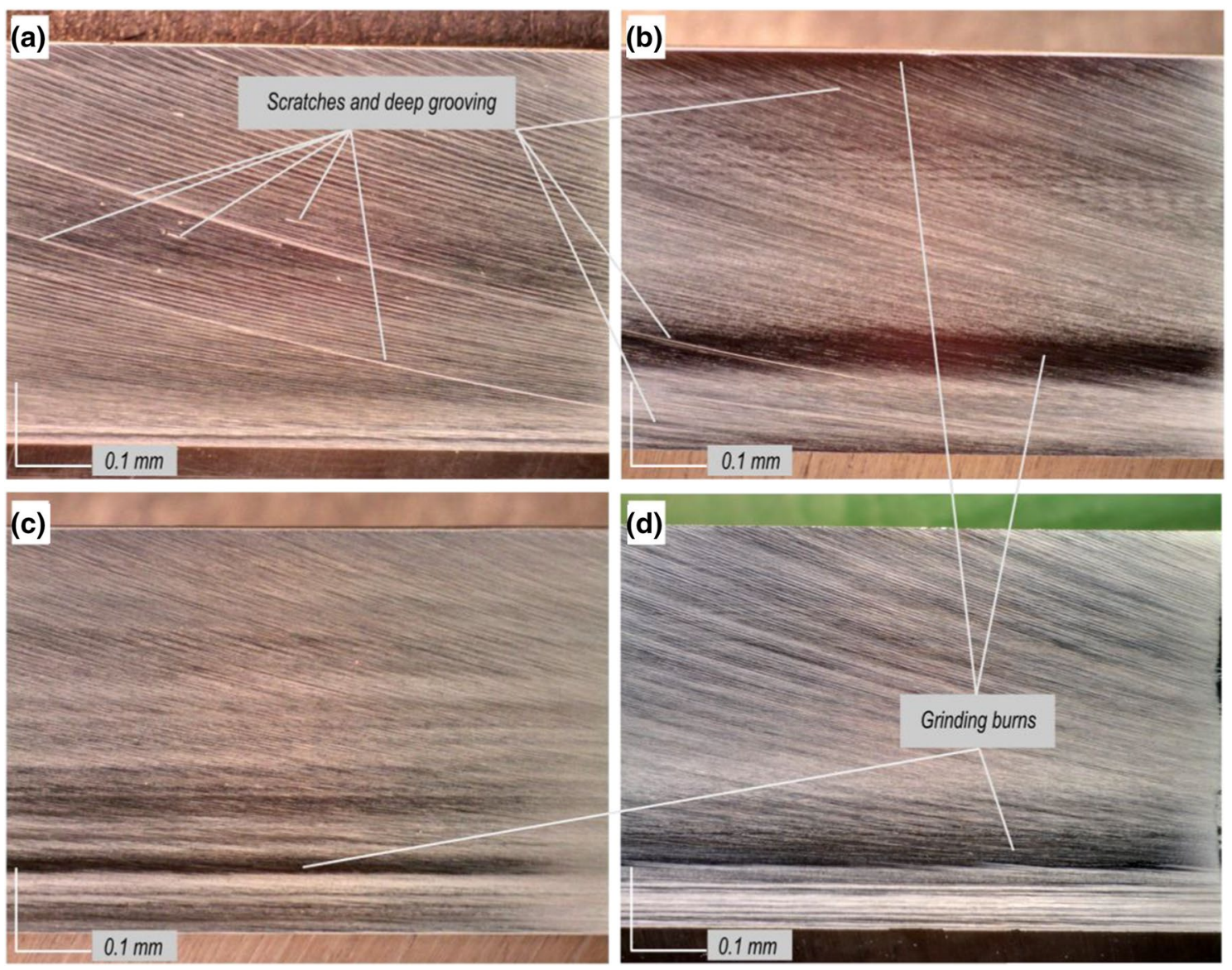

Fig. 12 Examples of surfaces with visible machining defects for grinding wheels with CBN grains of different sizes: a B54 $\left(a_{\mathrm{e}}=0.04 \mathrm{~mm}, v_{\mathrm{ft}}=700 \mathrm{~mm} / \mathrm{min}, n_{\mathrm{s}}=3000 \mathrm{rpm}\right), \quad$ b B54

separates areas with values lower than the adopted limit value of this index.

In analyzing the first pair of adjustable parameters of the grinding process (Fig. 14a), it should be concluded that the rotational speed of the grinding wheel has a more significant influence on the value of the quality index. The greater this is, the greater the probability of an increase in the $Q_{\mathrm{BL}}$ index, and thus the intensity of the occurrence of defects on the surface after machining. This trend is maintained across the entire broadly analyzed range of the working engagement. The zone of desirable, low values regarding the $Q_{\mathrm{BL}}$ error rate, limits the use of the grinding wheel spindle revolutions to the range of 2000-2500 rpm. Due to the slope of the boundary curve, it can be assumed that the greater the depth of cut, the higher the speed that can be used.

By comparing the two main speeds of the grinding process (Fig. 14b), often analyzed together in the form of the $q$ index, a very limited range of the required values of the rotational speed $n_{\mathrm{s}}$, strongly dependent on the choice of the feed rate $v_{\mathrm{ft}}$, is clearly visible. When using workpiece feed rates from 130 to about $470 \mathrm{~mm} / \mathrm{min}$, the rotational speed

$\left(a_{\mathrm{e}}=0.02 \mathrm{~mm}, \quad v_{\mathrm{ft}}=130 \mathrm{~mm} / \mathrm{min}, \quad n_{\mathrm{s}}=4600 \mathrm{rpm}\right), \quad$ c $\quad \mathrm{B} 107$ $\left(a_{\mathrm{e}}=0.08 \mathrm{~mm}, \quad v_{\mathrm{ft}}=130 \mathrm{~mm} / \mathrm{min}, \quad n_{\mathrm{s}}=3000 \mathrm{rpm}\right), \quad$ d $\quad \mathrm{B} 151$ $\left(a_{\mathrm{e}}=0.12 \mathrm{~mm}, v_{\mathrm{ft}}=130 \mathrm{~mm} / \mathrm{min}, n_{\mathrm{s}}=4600 \mathrm{rpm}\right)$

of the grinding wheel spindle should be limited to the minimum tested value, namely $1500 \mathrm{rpm}$. Only the use of higher feed rates (in experimental tests, respectively: 720 and $960 \mathrm{~mm} / \mathrm{min}$ ), allows the spindle speed to be increased even up to $2500 \mathrm{rpm}$, while still maintaining a relatively small percentage of defects on the machined surface.

The next graph (Fig. 14c) is characterized by a significant heterogeneity of the distribution of areas with different values of the defect rate on the surface after machining. A comparison of the feed rate and the value of the grinding wheel working engagement to the object being ground indicates two areas of interest. The first area lies at the intersection of the lowest depth of cut values $(0.02-0.04 \mathrm{~mm})$, as well as a feed rate of $800-960 \mathrm{~mm} /$ min. The second area shows a constant feed rate of $480 \mathrm{~mm} / \mathrm{min}$ when using large grinding depths $(0.12 \mathrm{~mm}$ and greater).

The next three charts were created as a graphical representation of the analysis of the impact of abrasive grain size on the quality index value of the ground surface. The first graph of this series (Fig. 14d) shows how the CBN grain 
Fig. 13 Character of topography of ground surface when changing feed rate of grinding table for $\mathrm{B} 151$ grinding wheel $\left(a_{\mathrm{e}}=0.02, n_{\mathrm{s}}=4600 \mathrm{rpm}\right)$ for different specific grinding volumetric efficiency $\left(Z^{\prime}\right): \mathbf{a} 0.04$ $\mathrm{mm}^{3} /(\mathrm{m} \mathrm{s}) ; \mathbf{b} 0.16 \mathrm{~mm}^{3} /(\mathrm{m} \mathrm{s}) ; \mathbf{c}$ $0.32 \mathrm{~mm}^{3} /(\mathrm{m} \mathrm{s})$

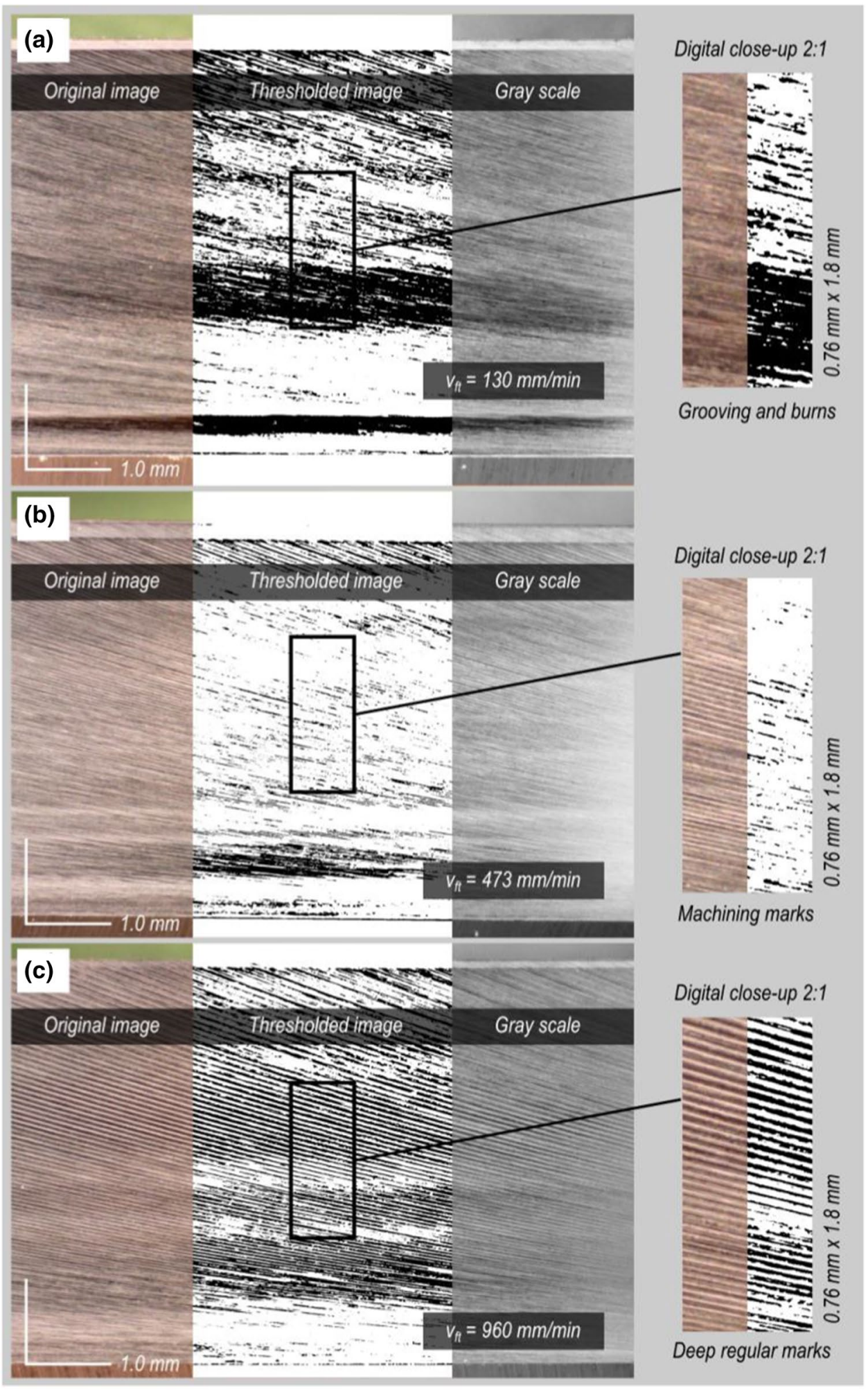

size as a function of the depth of cut $a_{\mathrm{e}}$ relates to the $Q_{\mathrm{BL}}$ index. The significant proportion of shades of blue indicates that there is no statistically significant correlation between the analyzed parameters. The medium turquoise area in Fig. $14 \mathrm{~d}$ is an area that has not been explored due to the too-high depth of cut in relation to the grain size and the risk of much faster wear of the abrasive grains under such machining conditions.

Although increasing the efficiency of the process by increasing the cross section of the cutting layer is acceptable, 
(a)

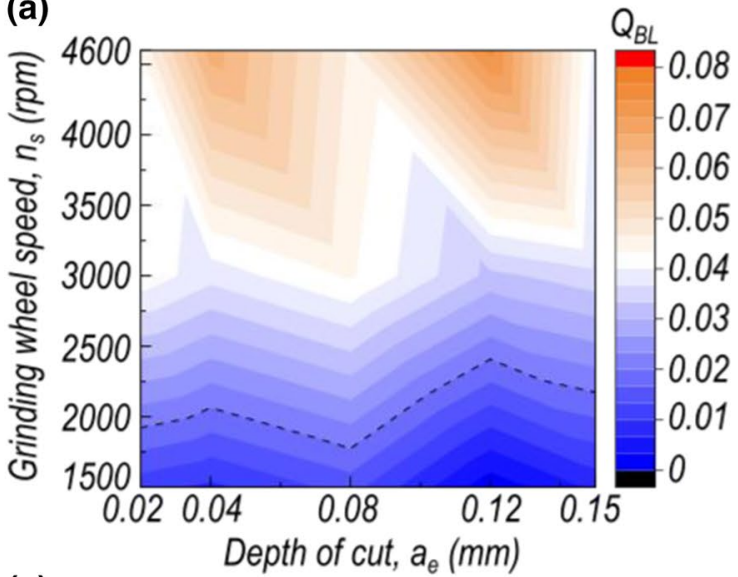

(c)

(c)

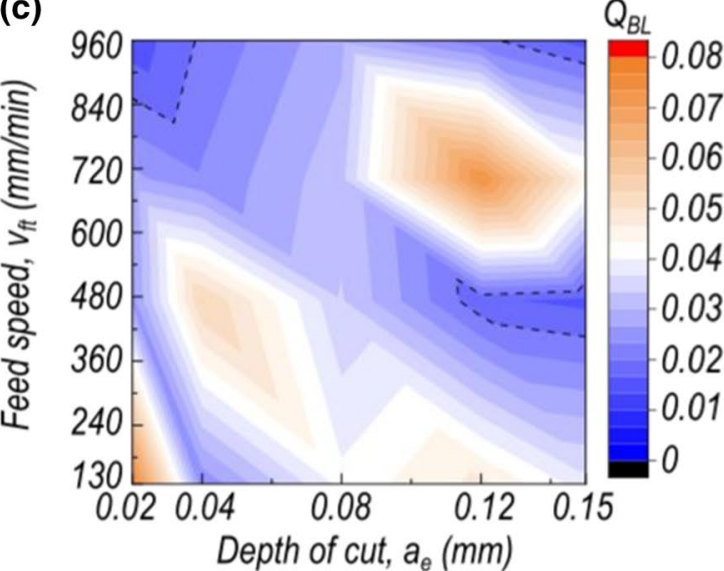

(e)

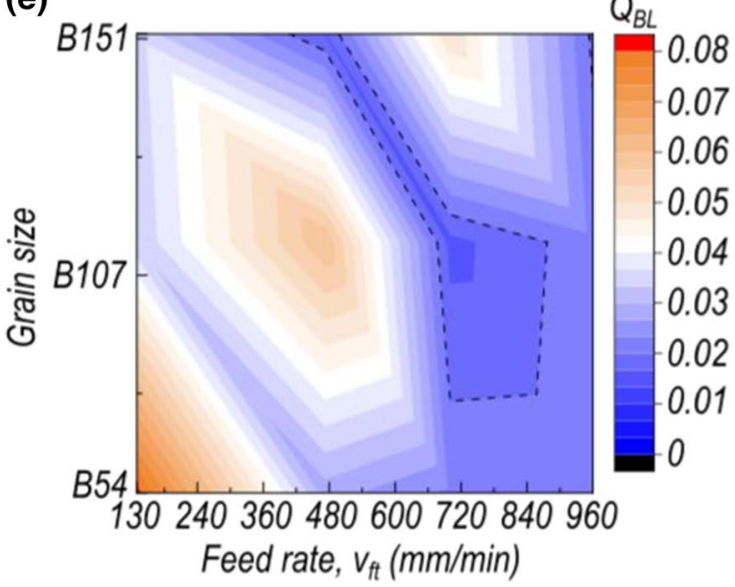

Fig. 14 Selected relationships between the proportion of defects on the clearance surface and the parameters of the grinding process: a influence of depth of cut and grinding wheel rotational speed; $\mathbf{b}$ influence of grinding wheel rotational speed and workpiece feed rate; $\mathbf{c}$

this may be disadvantageous due to the risk of lowering the surface quality. In this case, it is important to select the remaining machining parameters.

By analyzing the size of an abrasive grain, it is possible to indicate the recommended selection of the feed rate in the grinding process (Fig. 14e). For relatively large grains (b)

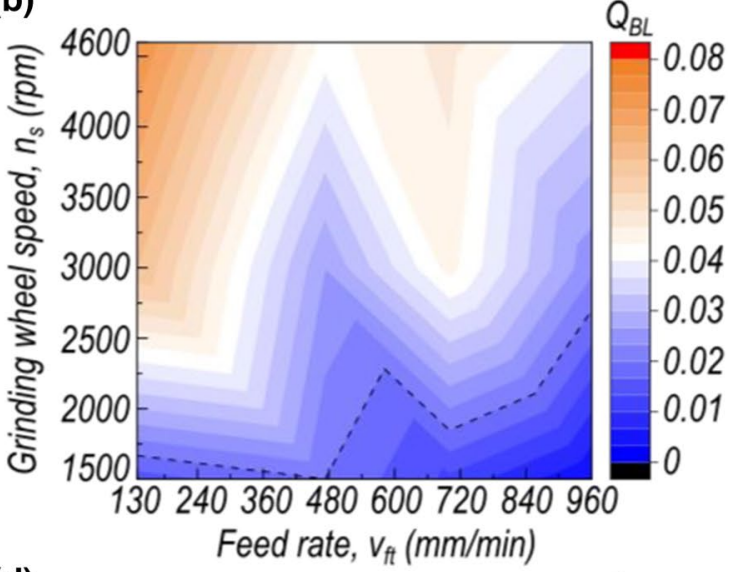

(d)

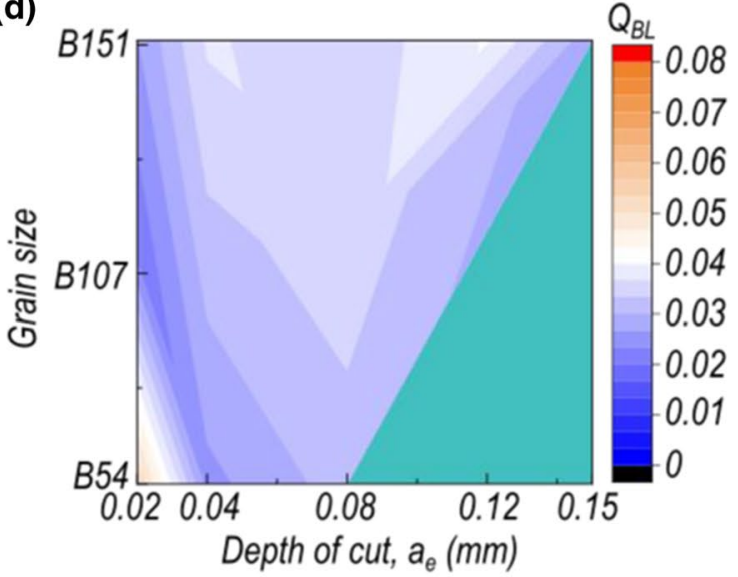

(f)

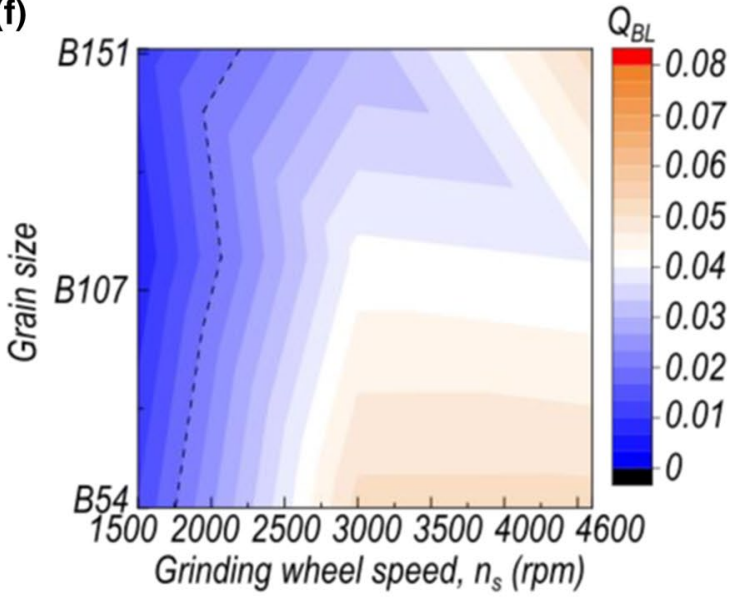

influence of depth of cut and feed speed; $\mathbf{d}$ influence of depth of cut when using grains different sizes; $\mathbf{e}$ influence of feed rate when using grains of different sizes; $\mathbf{f}$ influence of rotational speed when using grains of different sizes

(B151), the most favorable area of the process results was observed for the speed of $473 \mathrm{~mm} / \mathrm{min}$. When using a smaller grain (B107), the speed must be increased to at least $700 \mathrm{~mm} / \mathrm{min}$. Although the use of smaller grains (B54) 

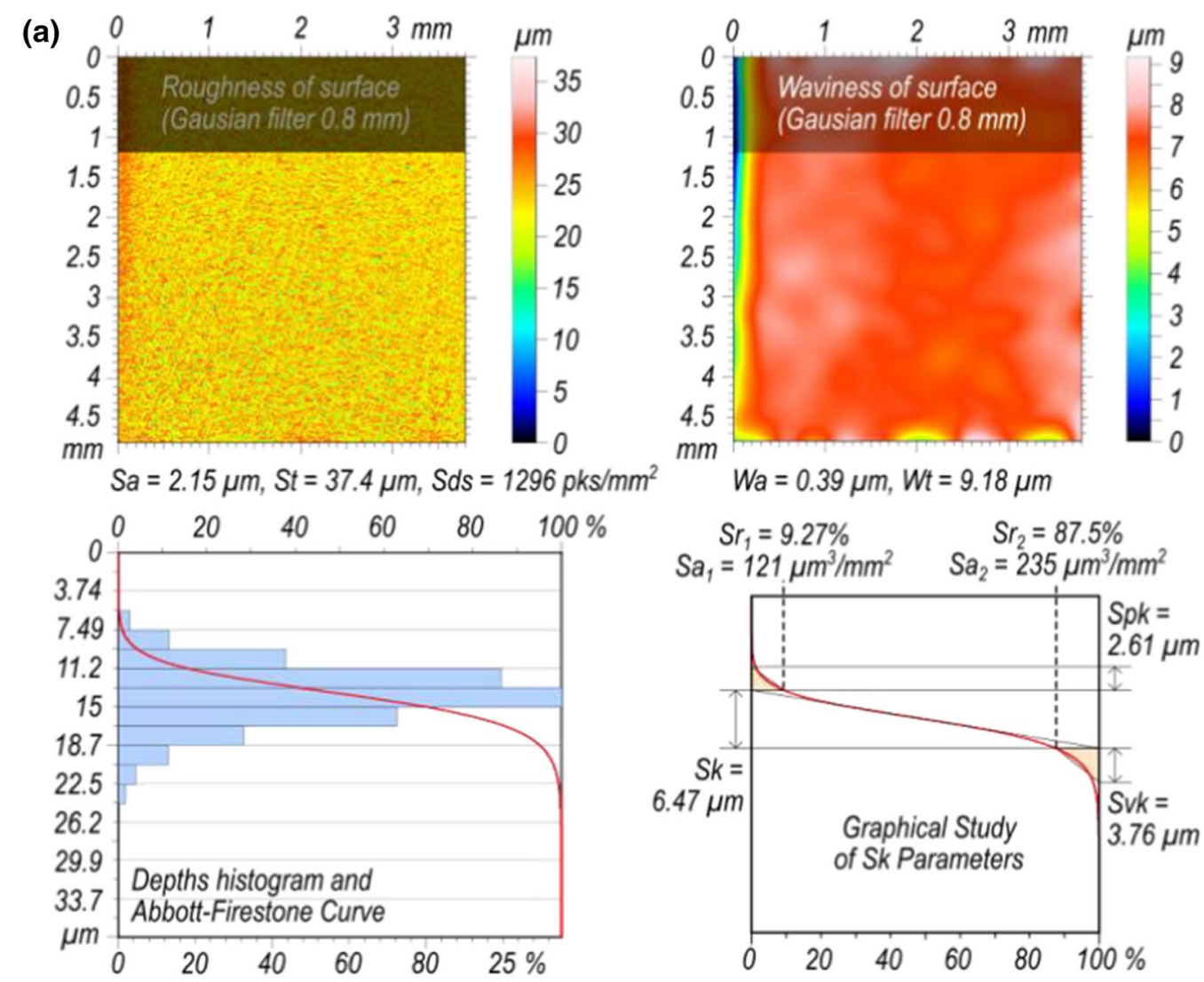

(b) $\begin{array}{lllll}0 & 1 & 2 & 3 \mathrm{~mm} \quad \mu \mathrm{m}\end{array}$
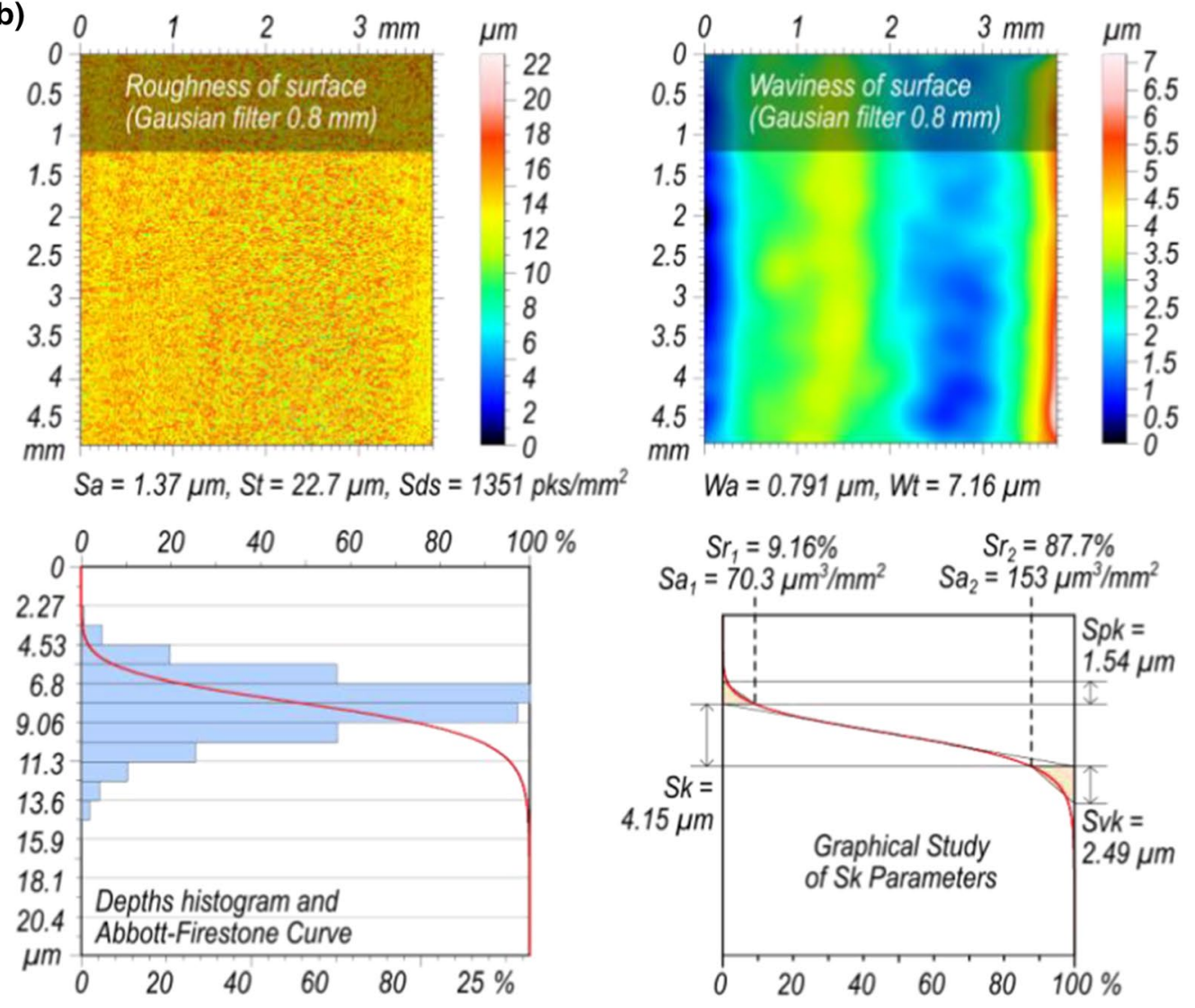
4Fig. 15 Selected topographic features of the tested surfaces in the form of contour maps, unevenness height distribution and the material ratio curve for the grinding process carried out with a CBN grinding wheel with B151 grains: a equivalent chip thickness $h_{\text {eq }}=0.03 \mu \mathrm{m}\left(Z^{\prime}=0.32 \mathrm{~mm}^{3} /(\mathrm{m} \mathrm{s})\right) ; \quad$ b equivalent chip thickness $h_{\mathrm{eq}}=0.08 \mu \mathrm{m}\left(Z^{\prime}=2.4 \mathrm{~mm}^{3} /(\mathrm{m} \mathrm{s})\right)$

also requires the use of high feed rates, this may be burdened with an increased number of defects on the machined surface.

Taking into account the results obtained in comparing the abrasive grain size with the rotational speed of the grinding wheel (Fig. 14f), it can be shown that it is preferable to use a low spindle speed, regardless of the grain size. This means that changing the grain size and switching from fine to coarse grinding has no effect on the speed selection. In relative terms, the largest grinding wheel with the largest grain size (B151) possesses the greatest tolerance in this regard. In this case, increasing the speed $n_{\mathrm{s}}$, for example, to a value of about $2500 \mathrm{rpm}$, did not significantly increase defects observed on the surface after the machining process.

\subsection{Surface roughness}

An analysis of the geometric microstructure of the clearance surface of planer knives allowed one to determine its stereometric features in terms of roughness and waviness. Shape errors were omitted by filtering out the nominal surface shape.

Figure 15 shows exemplary surface topographic features in the form of contour maps, determined for the S-L surface type, i.e. after removing the long-term (long-wave) components and by analyzing surface waviness.

The character of the surface roughness height distribution was examined by analyzing the depths histogram (density of the distribution of the data points in the surface), as well as by determining the bearing area curve (Abbott-Firestone Curve, AFC) with the calculation of the reduced peak height $S p k$, core roughness depth $S k$, reduced valley depth $S v k$ and the material values ratio at the point where the peak zone changes into the core zone, and at the point where the core zone changes into the valley zone. On the basis of these parameters, conclusions can be drawn about the tribological features of the contact surfaces of the tested knives, defining their practical functions.

The statistical comparison of the results of the research for selected parameters of the surface topography is included in Table 4 and with the division into the size of the abrasive grain in a graphic form in Fig. 16.

By analyzing the distributions of the values of individual parameters characterizing the geometric microstructure of the ground surface, assumptions were made regarding the critical values that may constitute the limit when determining the surface quality. These values in Figs. 16, $17,18,19$ are indicated by the dashed line and the preferred range (shaded area). The reference point here was the set of values of a given parameter obtained while conducting measurements for new knives, sharpened by the manufacturer. The proposed critical value was mostly set between the mean value of a given parameter, in order that the area also included at least one representative result for knives prepared by Leitz GmbH \& Co. KG. The exception is the critical value of the $S v k / S p k$ (reduced valley depth ratio to reduced peak height), set at $20 \%$.

To determine the quality of the shaped surface and its operational properties, the dominant feature of a given surface was additionally determined using $r w$ coefficients (cutoff value $\lambda_{c}=0.8 \mathrm{~mm}$ was used for all examined surfaces to separate waviness and roughness profiles):

$r w(a)=\mathrm{Sa} / \mathrm{Wa}$,

$r w(t)=\mathrm{St} / \mathrm{Wt}$.

An analysis of the obtained values indicates that roughness was the dominant feature of the surface after machining, which is reflected in the value of roughness to waviness relation ratio $r w>1$. In such cases, waviness may be omitted in the analysis of its impact on the quality and operational characteristics of the surface.

Values of $r w(a)<1$, indicating a relatively high proportion of waviness in the surface profile, were obtained for grinding with a grinding wheel with a small grain (B54) and a high depth of cut $\left(a_{\mathrm{e}}=0.8 \mathrm{~mm}\right)$. This may indicate the selection of too large a depth for the grain size and giving rise to vibrations of the OUPN system, or the occurrence of "burnishing" of the surface being machined. The impact of the burnishing process in relation to the turning and grinding process regarding the proportion of the waviness profile in the geometric structure of the surface has been discussed, among others, by Dzionk and Przybylski in the study [28].

The absolute values of the skewness parameter for most measurements of the ground surface topography differ from the zero value, which indicates that the distribution of the properties of the examined roughness parameters differs from the symmetric distribution. However, adopting the rule after Bulmer [29] that a skewness parameter for the G1 test in the range from -0.5 to +0.5 indicates a more or less symmetric distribution, all parameters, except for the parameters determining the total unevenness of surface roughness $(S t)$, waviness ( $W t)$ and reduced peak height (Spk), are characterized by a distribution with non-significant asymmetry.

It was observed in the tests, however, that flattening (kurtosis, G2) is negative in most cases, which means that the distribution of the surface topography feature values is less concentrated than in a normal distribution. Only in the case 
Table 4 Summary of selected statistics of topographic parameters for the analyzed graphs (sample size $n=90$ )
Fig. 16 Graphical representation of distribution of roughness parameters values and surface waviness after grinding process: a arithmetic mean of the absolute values of surface height deviations from the mean surface; $\mathbf{b}$ total surface unevenness; $\mathbf{c}$ number of peaks per unit area (surface peak density); d relationship of proportion of valley depth to height of peaks; e arithmetic mean of surface waviness deviations; $\mathbf{f}$ total waviness height

\begin{tabular}{|c|c|c|c|c|c|c|c|c|}
\hline \multirow[t]{2}{*}{ Parameter } & \multirow[t]{2}{*}{ Average value } & \multirow{2}{*}{$\begin{array}{l}\text { Standard } \\
\text { deviation }\end{array}$} & \multirow{2}{*}{$\begin{array}{l}\text { Standard } \\
\text { deviation } \\
\text { error }\end{array}$} & \multicolumn{2}{|c|}{ Skewness } & \multicolumn{2}{|c|}{ Excess kurtosis } & \multirow[t]{2}{*}{ Interval } \\
\hline & & & & $G_{1}$ & $Z_{\mathrm{g} 1}$ & $G_{2}$ & $Z_{\mathrm{g} 2}$ & \\
\hline$S a, \mu \mathrm{m}$ & 1.85 & 0.40 & 0.578 & -0.140 & -0.55 & -0.776 & -1.54 & 1.76 \\
\hline$S t, \mu \mathrm{m}$ & 32.04 & 5.48 & 0.042 & 0.771 & 3.03 & 1.560 & 3.10 & 30.76 \\
\hline$S d s$, peaks $/ \mathrm{mm}^{2}$ & 1256.15 & 75.63 & 7.972 & 0.336 & 1.32 & -0.813 & -1.62 & 333.67 \\
\hline$S k, \mu \mathrm{m}$ & 5.62 & 1.36 & 0.144 & 0.041 & 0.16 & -0.919 & -1.83 & 5.76 \\
\hline$S p k, \mu \mathrm{m}$ & 2.60 & 0.57 & 0.060 & -0.652 & -2.57 & -0.473 & -0.94 & 2.29 \\
\hline$S \nu k, \mu \mathrm{m}$ & 2.85 & 0.50 & 0.052 & -0.398 & -1.57 & -0.223 & -0.44 & 2.46 \\
\hline$W a, \mu \mathrm{m}$ & 0.98 & 0.47 & 0.050 & 0.418 & 1.64 & -0.667 & -1.33 & 1.82 \\
\hline$W t, \mu \mathrm{m}$ & 11.78 & 5.17 & 0.545 & 0.769 & 3.03 & 0.020 & 0.04 & 22.19 \\
\hline$r w(a)$ & 2.50 & 1.65 & 0.17 & 1.60 & 6.30 & 3.25 & 6.46 & 9.22 \\
\hline$r w(t)$ & 3.28 & 1.61 & 0.17 & 1.30 & 5.12 & 1.88 & 3.74 & 8.07 \\
\hline
\end{tabular}
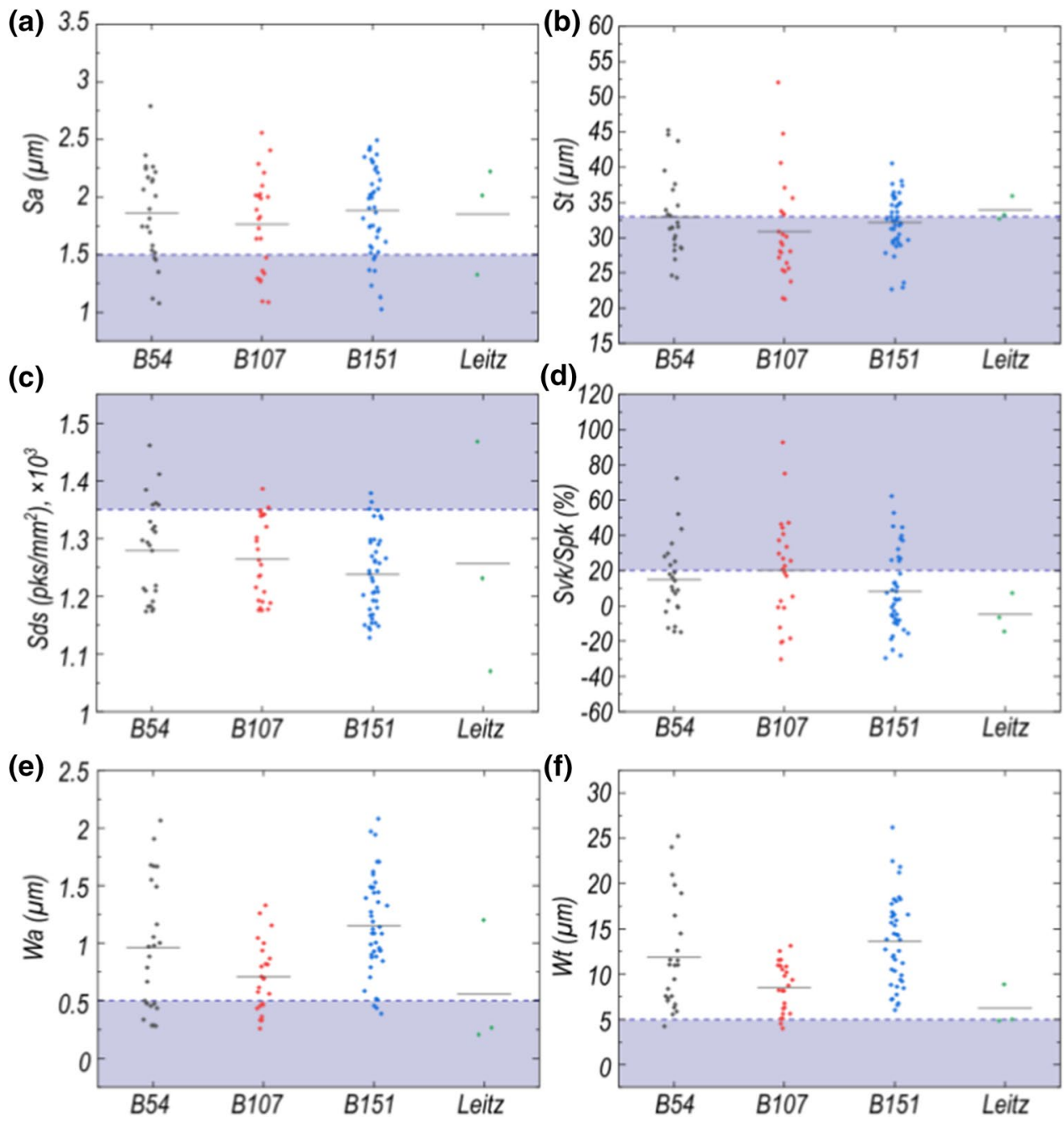

of the parameter describing the surface total height of waviness $(W t)$, was a distribution obtained with a concentration very close to a normal distribution (for which excess kurtosis is equal to 0 ).
However, considering that the calculated statistical test values for asymmetry $\left(Z_{\mathrm{g} 1}\right)$ and kurtosis $\left(Z_{\mathrm{g} 2}\right)$ mostly range between -1.96 and +1.96 (critical value of a normal distribution), the results can be considered acceptable evidence 


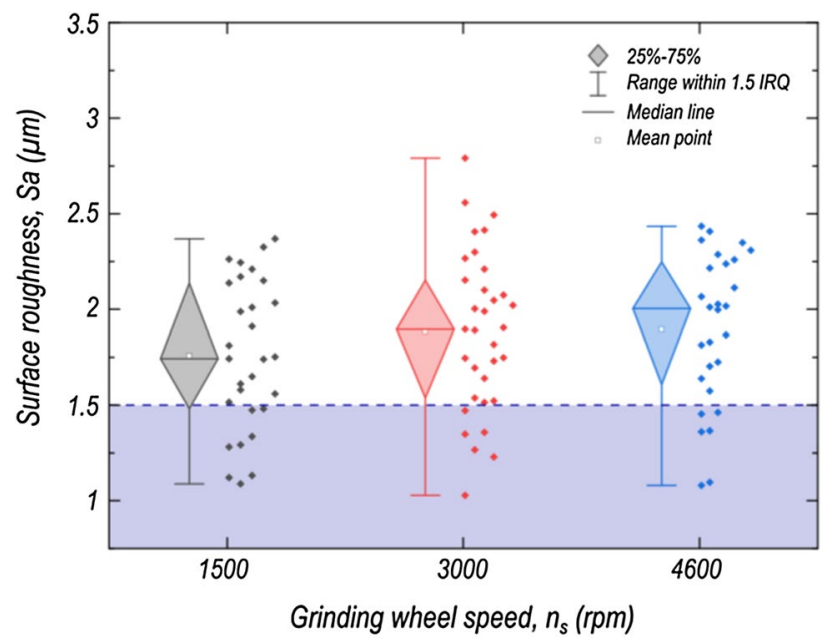

Fig. 17 Distribution of arithmetic mean surface roughness in relation to rotational speed of grinding wheel spindle

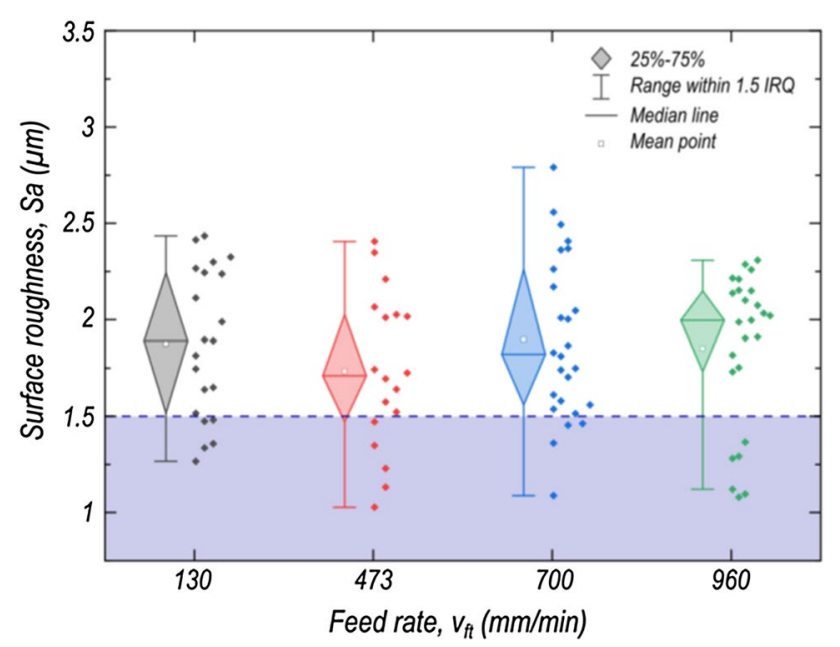

Fig. 18 Distribution of arithmetic mean surface roughness versus feed rate in the grinding process

(at a level of significance of 5\%) to describe the data with a normal distribution. This means that the mean values of $S a, S d s, S k, S v k$ and $W a$ determined on the basis of the research sample are close to the values for the entire population. Therefore, when conducting the process of grinding planer knives on the Weinig Rondamat 980 grinder with CBN grinding wheels possessing a ceramic bond, it should be expected to obtain a surface with a roughness of $S a=1.8 \mu \mathrm{m}$, with an average micro-unevenness density of $S d s=1250$ peaks $/ \mathrm{mm}^{2}$. The mean arithmetic height of unevenness for the surface waviness profile $(\mathrm{Wa}$ ) should not significantly differ from the value of $1 \mu \mathrm{m}$ after the grinding process. The expected values of the core roughness depth $(S k)$ and valley depth $(S v k)$, significant from the tribological point of view, are $5.6 \mu \mathrm{m}$ and $2.85 \mu \mathrm{m}$, respectively. The

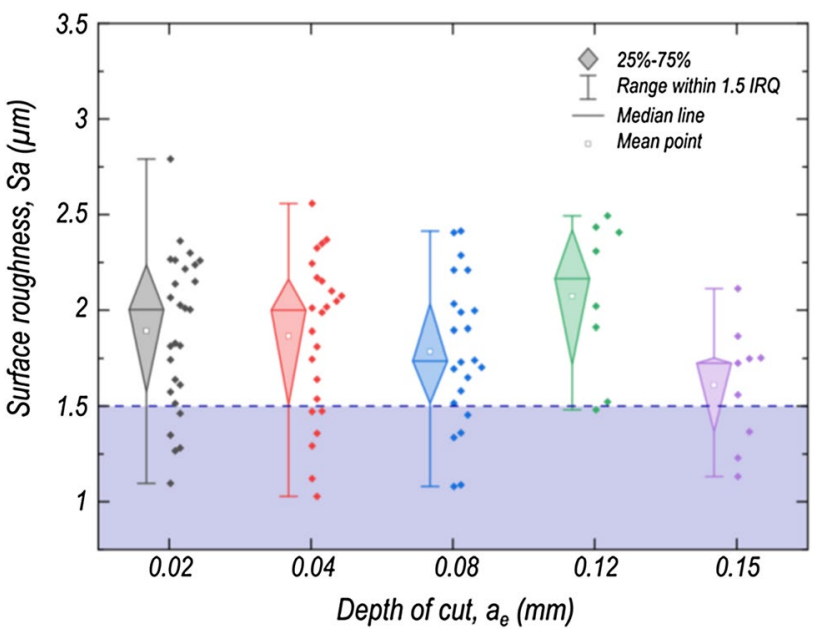

Fig. 19 Distribution of arithmetic mean surface roughness in relation to depth of cut in the grinding process

arithmetic mean of the surface roughness $(\mathrm{Sa})$ is distributed symmetrically with respect to the mean value for each size of a tested CBN grain. The values of this parameter do not differ significantly from each other, which means that, on this basis, one cannot clearly reject any size of abrasive grains as unsuitable for the grinding process.

The regions of variability of the recorded values for the waviness parameters $(\mathrm{Wa}, \mathrm{Wt})$ are the most concentrated and, at the same time, low in the case of an intermediate size of abrasive grain (B107). The situation is somewhat different in the case of the parameter defining the total height of surface roughness after grinding. Although the $S t$ parameter reaches the lowest values for grain B107, due to the greater dispersion of values and the occurrence of extreme values, grain B151 seems to be the best choice in terms of limiting the occurrence of micro-unevenness on the surface of high peaks.

The following graphs (Figs. 17, 18, 19) show the variability of the distribution of measuring points determining the surface roughness in relation to the feed rate and the grinding wheel rotational speed, along with the grinding depth. The graphs show the basic statistics: $25 \%$ and $75 \%$ percentiles, the range defining the limit of outliers, defined as 1.5 of the interquartile range, as well as the median and mean values.

From the position and shape of the box graph in Fig. 17, it can be inferred that roughness (Sa) increases with increasing grinding wheel rotational speed $\left(n_{\mathrm{s}}\right)$, which is due to an everhigher median value. However, the problem is the large data range and the location of the arthritic mean value far below the median for a speed of $4600 \mathrm{rpm}$. This factor indicates that the relationship is not clear.

In the case of the workpiece feed rate analysis, it should be concluded that this technological parameter has a 
proportional influence on surface roughness in the range of $473-960 \mathrm{~mm} / \mathrm{min}$ (Fig. 18). Only the results measured for the lowest feed value, equal to $130 \mathrm{~mm} / \mathrm{min}$, differ from this relationship. A point distribution indicates that the preferred feed rate, which may increase the likelihood of obtaining lower heights of surface micro-unevenness in the grinding of planer knives on the Rondamat 980 , is $473 \mathrm{~mm} / \mathrm{min}$.

Based on the observation of the median value and the average depth of cut in the grinding process determined for individual groups, one should conclude that increasing the feed rate has a positive effect on the process result, described by the surface roughness parameter $\mathrm{Sa}$ (Fig. 19). The greater the grinding depth $a_{\mathrm{e}}$, the lower the expected $S a$ value. The significant deviation from this rule at a depth of $0.12 \mathrm{~mm}$ disrupts the possible decision-making process to indicate a convenient choice of depth of cut.

Although the density of the distribution of the data points on the surface, comparing the application of the two extreme depths of cut, is in both cases similar to the normal distribution, the heights change at individual intervals (Fig. 15). In the case of $a_{e}=0.02 \mathrm{~mm}$ (with $h_{e q}=0.03 \mu \mathrm{m}$ ), the data obtained empirically indicate that the peaks with a height between $11.2 \mu \mathrm{m}$ and $15 \mu \mathrm{m}$ constitute the highest percentage in the shaping of the surface topography (about $25 \%$ ). For $a_{e}=0.15 \mathrm{~mm}$ (with $h_{e q}=0.08 \mu \mathrm{m}$ ), this interval is between 6.8 and $9.06 \mu \mathrm{m}$. The difference between the compared topographies is reflected by the parameter $S k$, equal to $6.47 \mu \mathrm{m}$ and $4.15 \mu \mathrm{m}$, respectively. These results are significant because of their contrary nature with regard to typical relationships between roughness and grinding conditions, where the arithmetic mean deviation of the roughness profile $(R a)$ increases with an increasing depth of cut or feed rate, and decreases with an increasing rotational speed of the grinding wheel (see Eqs. 3, 6). The results of the experimental tests carried out indicate, however, that instead of increasing, roughness decreases with increasing depth of cut, while the simultaneous increase in speed $v_{s}$ does not compensate for this effect. Against the not-completely-clear $S a=f\left(v_{\mathrm{ft}}\right)$ relationship, this proves the dominant influence of the grinding depth on the height of the micro-unevenness of a ground surface.

The individual parameters of the grinding process can be included in a synthetic analysis of the effect of the equivalent chip thickness parameter $h_{\mathrm{eq}}$ on surface roughness expressed by $S a$ (Fig. 20a). Reducing the thickness of a single-grain cut layer usually results in a reduction in the roughness profile height. However, in the test process, machining with low equivalent chip thickness $\left(h_{\text {eq }}\right)$ values does not indicate such a qualitative result of the grinding operation. Taking into account the distribution of measuring points and the shape of the surface determined at the points connecting the depth of cut $a_{\mathrm{e}}$ and the speed ratio $q$
(Fig. 20b), areas with low surface roughness unevenness $(S a<1.1 \mu \mathrm{m})$ can be indicated-Table 5 .

Figure 20 shows the variation of the Sa parameter as a function of the parameters determining the dynamics of the process and the loading of the grinding zone. None of the parameters characterizing the machining process, i.e. the equivalent chip thickness $\left(h_{\mathrm{eq}}\right)$, the specific grinding volumetric efficiency $\left(Z^{\prime}\right)$ and the relationship of the main grinding speeds $(q)$, were obtained in studies of correlation that can be described by a statistically significant function. It should be emphasized that the results presented here were determined by analyzing all the results obtained for both the three CBN grain sizes $(54,107$ and 151) and a wide range of depth of cut values (from 0.02 to $0.15 \mathrm{~mm}$ ). This means that for a wide range of settings for the grinding process, both relatively low and high roughness surfaces can be obtained.

A relatively clear relationship can be determined by analyzing the influence of the feed rate and the rotational speed of the grinding wheel spindle on the average value of absolute surface micro-unevenness deviations (Fig. 20f). The graph reveals the range of values conducive to shaping surfaces with low and high $S a$ values. To obtain a surface with a relatively low arithmetic mean roughness height $(S a<1.5 \mu \mathrm{m})$, the grinding process should be carried out at an average feed rate (range $v_{\mathrm{ft}}=400-600 \mathrm{~mm} / \mathrm{min}$ ), while using the same low speed of the grinding wheel (e.g. $\left.n_{\mathrm{s}}=2000 \mathrm{rpm}\right) / \mathrm{min}$ ).

By projecting the results from Fig. 20f onto a plane, one can read the mean values of surface roughness ( $\mathrm{Sa}$ parameter) obtained in the tests conducted (Fig. 21). The lowest average value of the Sa parameter $(1.13 \mu \mathrm{m})$ was recorded for a feed rate of $450 \mathrm{~mm} / \mathrm{min}$ and a rotational speed of $1500 \mathrm{rpm}$. Slightly higher roughness $(S a=1.50 \mu \mathrm{m})$ was recorded at an increased rotational speed (3000 rpm).

Adapted from Menzes et al., the concept can be employed, that the density of the peak distribution (and thus the average distances between the peaks on the roughness profile) may be a key parameter in the classification of the surface, especially its operational characteristics $[26,30]$. The way in which the peaks deform (in an elastic or plastic manner) under the impact of a load is related to their number. A low Sds can cause greater local contact stress, which can lead to pitting and contamination occurring on the surface during use. It is preferable to use surfaces with an increased peak density to maintain proper load distribution and reduce the friction coefficient. The mean value of the $S d s$ parameter for all tests was 1256.15 peaks $/ \mathrm{mm}^{2}$. Although for this parameter no information on any correlation with the grinding process settings was obtained, the most favorable machining conditions can be indicated $\left(n_{\mathrm{s}}=3000 \mathrm{rpm}, v_{\mathrm{ft}}=473 \mathrm{~mm} /\right.$ min)_Fig. 22 . 


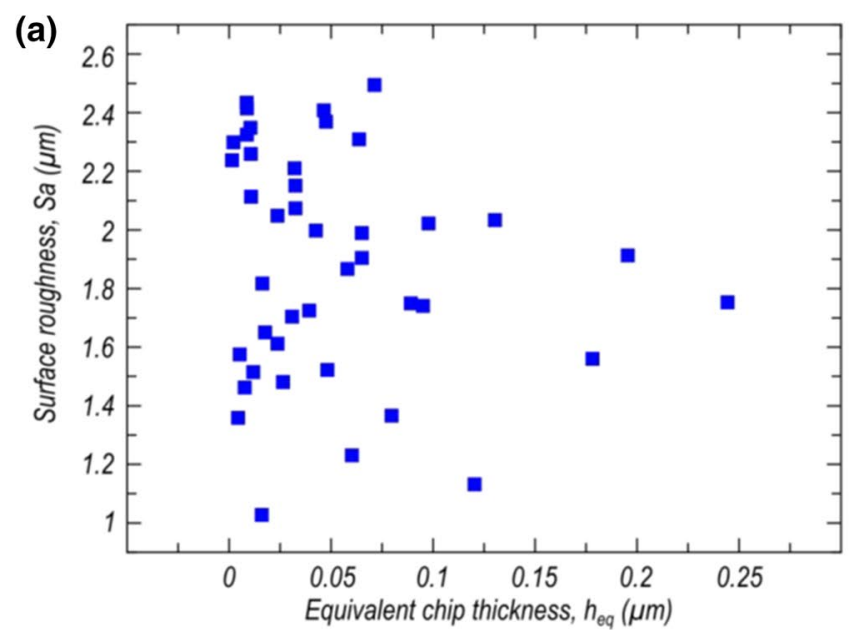

(c)

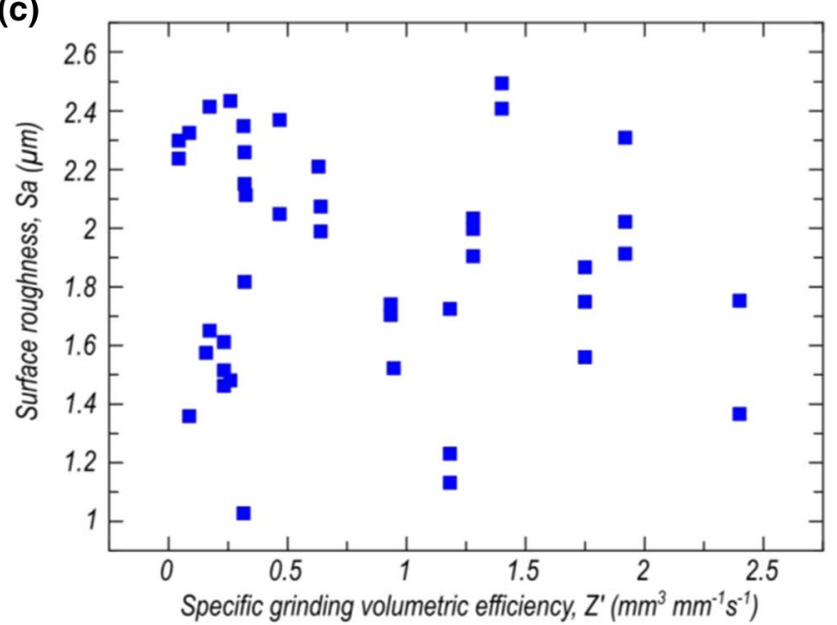

(e)

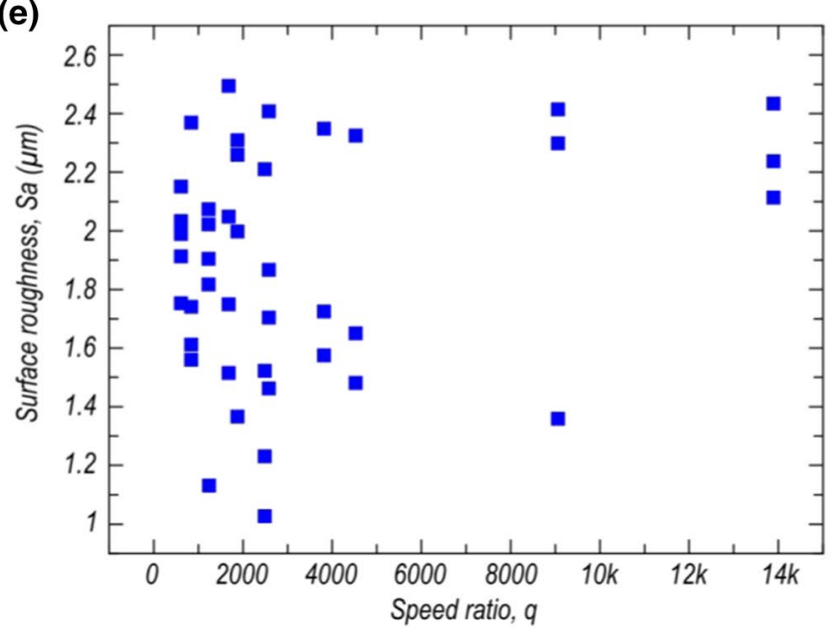

Fig. 20 Influence of selected coefficients characterizing the grinding process on surface roughness obtained in experimental tests: a influence of equivalent variability of hip thickness; $\mathbf{b}$ influence of quantities characterizing equivalent chip thickness; $\mathbf{c}$ influence of the (b)

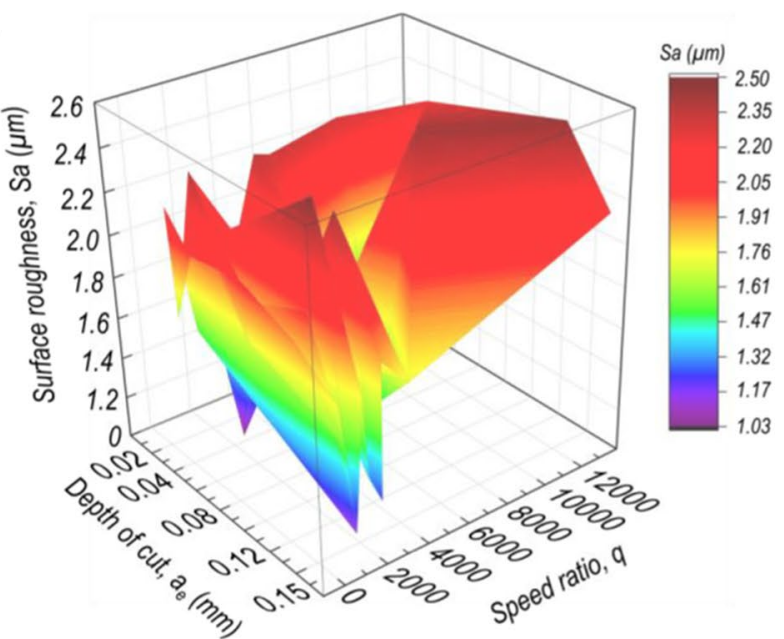

(d)

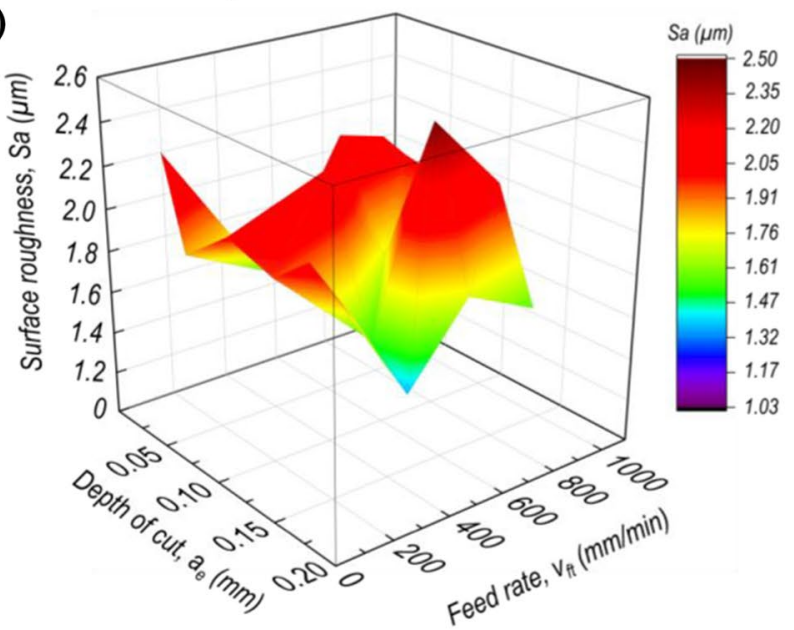

(f)

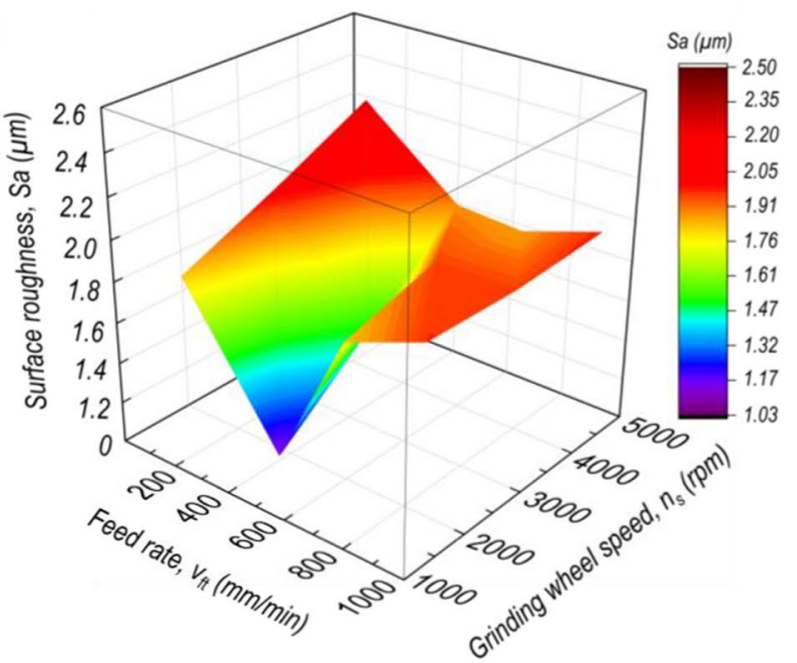

specific grinding volumetric efficiency; $\mathbf{d}$ influence of the quantities characterizing the specific grinding volumetric efficiency; $\mathbf{e}$ influence of the speed ratio; $\mathbf{f}$ influence of grinding wheel rotational speed and feed rate 
Table 5 List of grinding process parameters for which the lowest values of the arithmetic mean surface roughness were obtained

\begin{tabular}{llllll}
\hline$a_{\mathrm{e}}, \mathrm{mm}$ & $v_{\mathrm{ft}}, \mathrm{mm} / \mathrm{min}$ & $n_{s}, \mathrm{rpm}$ & $q$ & $h_{\mathrm{eq}}, \mu \mathrm{m}$ & Grain size \\
\hline 0.04 & 473 & 3000 & 2490 & 0.016 & B151 \\
0.08 & 700 & 1500 & 840 & 0.095 & B107 \\
0.02 & 960 & 4600 & 1880 & 0.010 & B107 \\
0.08 & 960 & 4600 & 1880 & 0.042 & B54 \\
\hline
\end{tabular}

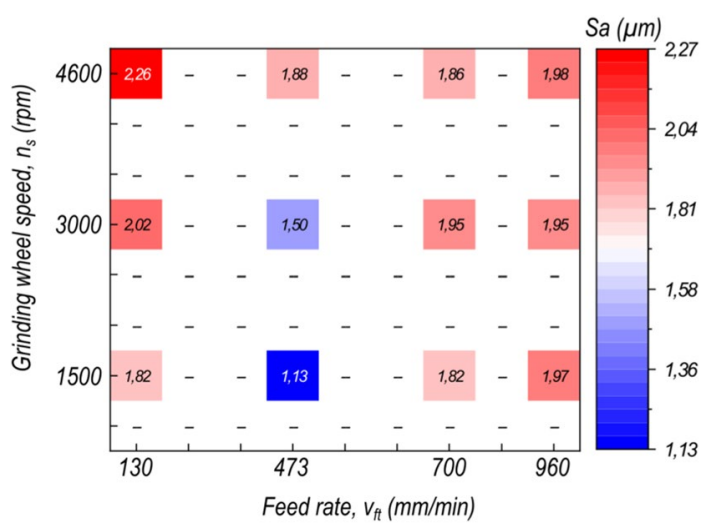

Fig. 21 Relationship of surface roughness in relation to selection of grinding wheel rotational speed and feed rate

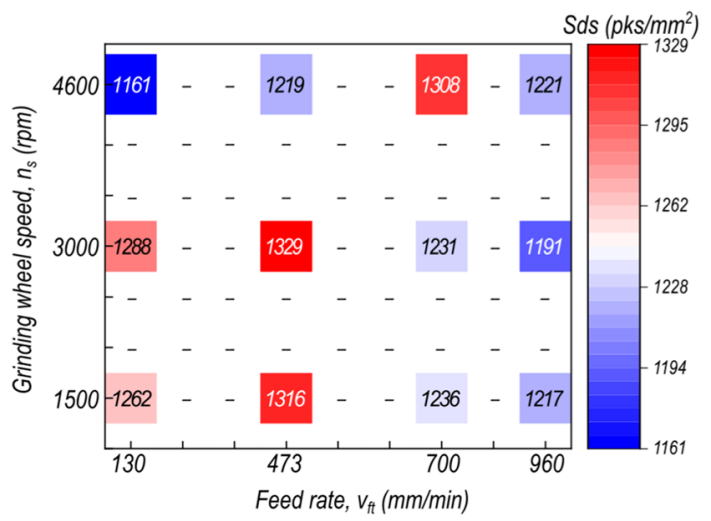

Fig. 22 Relationship of distance between peaks of roughness profile (peak density) in relation to selection of grinding wheel rotational speed and feed rate

\section{Conclusions}

A methodology for the regeneration process of planer knives for woodworking industry was discussed and proposed of specific parameters of the grinding process to eliminate worn edge displacement, obtain a high degree of sharpness and clearance surface with a quality index close to a sharp and unused knife. It was found the range of permissible parameters for machining with use Weinig Rondamat 980 in this regard. The results of experimental research revealed a clear specific nature of the process of grinding planer knives in the kinematic system offered by the Rondamat grinder. As a result, determining the ideal (optimal) conditions and parameters of the machining process, especially in the manner of an explicitly recorded multivariate relationship that would be statistically significant, is particularly difficult. The main limitations of use from the results from this study are cutting head assembly accuracy (preparation, external activities) and kinematics of grinding process, which procures many difficulties during sharpening. The most important and difficult to eliminate is burr formation issue.

A wide range of analyses of surface topography and quality following the regeneration process conducted under different conditions have allowed the following specific conclusions to be drawn:

The optical analysis of the clearance surface of planer knives showed that (depending on the selection of machining parameters) surfaces with a different distribution of micro-grooves, grooves and scratches can be obtained. The proposed grinding methodology allows obtaining a product of good quality.

Taking into account the statistical average results of grinding process, the roughness and waviness parameters of surface can be reduced in relation to new knife: by an $8 \%$-lower arithmetic mean peak height of microchips $(S a)$, a $22 \%$-lower reduced peak height $(S p k)$, with a similar roughness core height, and an $18 \%$-lower waviness surface height $(\mathrm{Wa})$.

The selection of the machining process conditions also determines the intensity of the process and the thermal impact of the grinding wheel on the machined surface, which may translate into local changes in the structure of the material, as revealed by grinding burns. It is preferable to use a CBN grain size of B107 or B151, a low depth of cut (e.g. $0.02 \mathrm{~mm})$, a moderate $(473 \mathrm{~mm} / \mathrm{min})$ or high feed rate $(960 \mathrm{~mm} / \mathrm{min})$ and a grinding wheel speed not exceeding $3000 \mathrm{rpm}$ to avoid this problem.

The conditions of the grinding process, selected in accordance with the principle: high feed rate, low spindle revolutions, may favorably shape the geometric structure of the surface in terms of its quality, which will be characterized by deep longitudinal microgrooves. In turn, this may favorably affect the efficiency of the planing process and increase tool life.

Research in discussed area should be continued, which will allow the grinding process parameters to be linked with the life cycle of planer knives in the planning process. 
Acknowledgements The authors wish to thank the following people for their contribution in carrying operational tests and measurements: employees of KPPD Kalisz Pomorski (Kalisz Pomorski, Poland) Mr. Damian Girtler, Mr. Artur Girtler, Mr. Marcin Kruk, Mr. Marek Litwin and Mrs. Kamila Szumowicz-Włodarczyk as well as employees of Koszalin University of Technology (Koszalin, Poland) - Mr. Krzysztof Maciejewski, Mr. Wojciech Zawadka, MSc, BSc and Mr. Stanisław Bokiej, BSc.

Author contributions Supervision, KN; conceptualization, AG, PM, $\mathrm{BW}$, and $\mathrm{KN}$; research methodology, MS, PS, investigation, MS, PS, and $\mathrm{AG}$; formal analysis, $\mathrm{KN}$, PS, PM, and BW; writing-original draft preparation, $\mathrm{KN}$ and PS; writing-review and editing, $\mathrm{KN}$ and PS. All authors have read and agreed to the published version of the manuscript.

Funding This document is the result of a research project funded by the Polish National Centre for Research and Development, project number BIOSTRATEG3/344303/14/NCBR/2018: Improvement of Process and Material Efficiency in Sawmill Industry under the BIOSTRATEG: Natural Environment, Agriculture and Forestry program.

Open Access This article is licensed under a Creative Commons Attribution 4.0 International License, which permits use, sharing, adaptation, distribution and reproduction in any medium or format, as long as you give appropriate credit to the original author(s) and the source, provide a link to the Creative Commons licence, and indicate if changes were made. The images or other third party material in this article are included in the article's Creative Commons licence, unless indicated otherwise in a credit line to the material. If material is not included in the article's Creative Commons licence and your intended use is not permitted by statutory regulation or exceeds the permitted use, you will need to obtain permission directly from the copyright holder. To view a copy of this licence, visit http://creativecommons.org/licenses/by/4.0/.

\section{References}

1. Knight WA, Boothroyd G. Fundamentals of metal machining and machine tools. Boca Raton: Taylor and Francis; 2006. (ISBN 9781574446593).

2. Cui X, Zhao J, Tian X. Cutting forces, chip formation, and tool wear in high-speed face milling of AISI H13 steel with CBN tools. Int J Adv Manuf Technol. 2013;64:1737-49. https://doi.org/10. 1007/s00170-012-4137-9.

3. Cui X, Zhao J, Dong Y. The effects of cutting parameters on tool life and wear mechanisms of CBN tool in high-speed face milling of hardened steel. Int J Adv Manuf Technol. 2013;66:955-64. https://doi.org/10.1007/s00170-012-4380-0.

4. Denkena B, Ortmaier T, Ahrens M, et al. Monitoring of grinding wheel defects using recursive estimation. Int $\mathbf{J}$ Adv Manuf Technol. 2014;75:1005-15. https://doi.org/10.1007/ s00170-014-6170-3.

5. Oraby SE, Hayhurst DR. Tool life determination based on the measurement of wear and tool force ratio variation. Int J Mach Tools Manuf. 2004;44(12-13):1261-9. https://doi.org/10.1016/j. ijmachtools.2004.04.018.

6. Astakhov VP. Effects of the cutting feed, depth of cut, and workpiece (bore) diameter on the tool wear rate. Int J Adv Manuf Technol. 2007;34:631-40. https://doi.org/10.1007/s00170-006-0635-y.

7. Sutowski P, Plichta S. An investigation of the grinding wheel wear with the use of root-mean-square value of acoustic emission. Arch
Civ Mech Eng. 2006;6(1):87-98. https://doi.org/10.1016/S16449665(12)60078-8.

8. Stein JL, Huh K. Monitoring cutting forces in turning: a modelbased approach. ASME J Manuf Sci Eng. 2000;124(1):26-31. https://doi.org/10.1115/1.1432666.

9. Kumar MK, Ghosh A. On grinding force ratio, specific energy, G-ratio and residual stress in SQCL assisted grinding using aerosol of MWCNT nanofluid. Mach Sci Technol. 2021;25(4):585607. https://doi.org/10.1080/10910344.2021.1903920.

10. Nadolny K, Kapłonek W, Sutowska M, et al. Moving towards sustainable manufacturing by extending the tool life of the pine wood planing process using the AlCrBN coating. Sustain Mater Technol. 2021;28: e00259. https://doi.org/10.1016/j.susmat.2021. e00259.

11. Nadolny K, Sienicki W, Wojtewicz M. The effect upon the grinding wheel active surface condition when impregnating with nonmetallic elements during internal cylindrical grinding of titanium. Arch Civ Mech Eng. 2015;15:71-86. https://doi.org/10.1016/j. acme.2014.03.004.

12. Yağmur $\mathrm{S}$. The effects of cooling applications on tool life, surface quality, cutting forces, and cutting zone temperature in turning of Ni-based Inconel 625. Int J Adv Manuf Technol. 2021;116:82133. https://doi.org/10.1007/s00170-021-07489-2.

13. Nadolny K, Wojtewicz M, Sienicki W, et al. An analysis of centrifugal MQL supply system potential in the internal cylindrical grinding process. Arch Civ Mech Eng. 2015;15:639-49. https:// doi.org/10.1016/j.acme.2014.08.009.

14. Nadolny K, Kapłonek W, Sutowska M, et al. Experimental studies on durability of PVD-based $\mathrm{CrCN} / \mathrm{CrN}$-coated cutting blade of planer knives used in the pine wood planing process. Materials. 2020;13(10):2398. https://doi.org/10.3390/ma13102398.

15. Nadolny K, Kapłonek W, Sutowska M, et al. Experimental tests of PVD AlCrN-coated planer knives on planing Scots pine (Pinus sylvestris L.) under industrial conditions. Eur J Wood Wood Prod. 2021;79:645-65. https://doi.org/10.1007/s00107-021-01660-y.

16. Gilewicz A, Goluch B, Kukliński Z, Warcholiński B. Selected mechanical properties of $\mathrm{AlCrN}$ coatings deposited using cathodic arc evaporation method (in Polish). Mechanik. 2016;5-6:538-9. https://doi.org/10.17814/mechanik.2016.5-6.75.

17. Gilewicz A, Kuznetsova T, Aizikovich S, et al. Comparative investigations of $\mathrm{AlCrN}$ coatings formed by cathodic arc evaporation under different nitrogen pressure or arc current. Materials. 2021;14(2):304. https://doi.org/10.3390/ma14020304.

18. Gochev Z, Vichev P. Determination of performance indicators of PCD abrasive wheels for sharpening tungsten carbide wood cutting tools. ACTA Fac Xylologiae Zvolen. 2020;62(2):109-14. https://doi.org/10.17423/afx.2020.62.2.10.

19. Gochev Z, Vichev P, Vukov G (2019) Determination of performance index and effective power for sharpening of TC planer knives with PCD abrasive wheels. In: ICWST 2019, implementation of wood science in woodworking sector and 70th anniversary of Drvna industrija Journal, Zagreb, pp 53-60 (ISBN 978-953-292-06-8)

20. Gochev Z, Vichev P, Vukov G (2019) Determination of performance indicators and quality of TCT knives when sharpened with PCD grinding wheels. In: Wood technology \& product design. Ss. Cyril and Methodius University, Skopje, pp 119-126 (ISBN: 978-608-4723-03-5)

21. Gochev Z (2008) Investigation on the grinding quality of planing knives made of high-speed steel (HSS) type M2 and specific consumption of cubic boron nitride (CBN). In: Chip and chipless woodworking processes. Technical University in Zvolen, Zvolen, 89-97 (ISBN: 978-80-228-1913-8)

22. Nadolny K, Kapłonek W. SEM-based morphological analysis of the new generation AION-based abrasive grains (Abral ${ }^{\circledR}$ ) 
with reference to $\mathrm{Al}_{2} \mathrm{O}_{3} / \mathrm{SiC} / \mathrm{cBN}$ abrasives. Acta Microsc. 2015;24(1):64-78.

23. O'Connor RF, Tomlinson WJ, Blunt LA. Effect of waviness on the wear behaviour of 080 M40 (EN8) and 817 M40 (EN24A) steels. Tribol Int. 1991;24(5):259-68. https://doi.org/10.1016/ 0301-679X(91)90028-8.

24. $\mathrm{Cz} €$. Identification of machining marks on abrasive treated surfaces, using image processing techniques. Mechanik. 2018;91(11):1020-2. https://doi.org/10.17814/mechanik.2018. 11.181.

25. Giovannini M, Moser N, Ehmann K (2015) Experimental and analytical study of micro-serrations on surgical blades. In: Conference: ASME 2015 international technical conference and exhibition on packaging and integration of electronic and photonic microsystems collocated with the ASME 2015, 13th International conference on nanochannels, microchannels and minichannels. V003T03A004. https://doi.org/10.1115/IPACK2015-48046

26. Menezes PL, Kailas SV. Role of surface texture and roughness parameters on friction and transfer film formation when UHMWPE sliding against steel. Biosurf Biotribol. 2016;2(1):1-10. https://doi.org/10.1016/j.bsbt.2016.02.001.
27. Lebedev V, Klimenko N, Uryadnikova I et al (2017) Martensite transformations in the surface layer at grinding of parts of hardened steels. East Eur J Enterp Technol 3(12(87)):56-63. https:// doi.org/10.15587/1729-4061.2017.103149

28. Dzionk S, Przybylski W. Surface waviness of components machined by burnishing method. Arch Mech Technol Autom. 2012;32(3):25-33.

29. Bulmer MG. Principles of statistics. New York: Dover Publications Inc; 1979. (ISBN 978-0486637600).

30. Menezes PL, Kishore KSV. Influence of roughness parameters on coefficient of friction under lubricated conditions. Sadhana. 2008;33(3):181-90. https://doi.org/10.1007/s12046-008-0011-8.

Publisher's Note Springer Nature remains neutral with regard to jurisdictional claims in published maps and institutional affiliations. 